\title{
A COMPREHENSIVE ANALYSIS OF NEUROTROPHINS AND NEUROTROPHIN TYROSINE KINASE RECEPTORS EXPRESSION DURING DEVELOPMENT OF ZEBRAFISH
}

Running Title: $n t$ and $n t r k$ expression in zebrafish embryos.

Valeria Nittoli ${ }^{1, \#}$, Rosa M. Sepe ${ }^{1, \#}$, Ugo Coppola ${ }^{1, \#}$, Ylenia D'Agostino ${ }^{1}$, Elena De Felice ${ }^{1,2}$, Antonio Palladino ${ }^{1}$ Q Quirino A. Vassalli ${ }^{1}$, Annamaria Locascio ${ }^{1}$, Filomena Ristoratore ${ }^{1}$, Antonietta Spagnuolo ${ }^{1}$, Salvatore D'Aniello ${ }^{1}$, Paolo Sordino ${ }^{1,}$

\section{Affiliations:}

${ }^{1}$ Department of Biology and Evolution of Marine Organisms, Stazione Zoologica Anton Dohrn, Villa Comunale, 80121, Naples, Italy.

2 Current address: School of Biosciences and Veterinary Medicine, University of Camerino, Italy.

\# First equal authors.

* Correspondence to:

Paolo Sordino, Ph.D.

Department of Biology and Evolution of Marine Organisms, Stazione Zoologica Anton Dohrn,

Villa Comunale, 80121, Naples, Italy.

Phone: $39-081-5833283$

Fax: 39-081-7641355

E-mail: paolo.sordino@szn.it

Acknowledgements: This work was funded by a FIRB grant (RBFR12QW4I) to S. D'Aniello and a PON grant (a3_00239) to P. Sordino from Italian Ministry of Education, University and Research (MIUR). We are grateful to Enrico D'Aniello for help in anatomical assignments.

This article has been accepted for publication and undergone full peer review but has not been through the copyediting, typesetting, pagination and proofreading process which may lead to differences between this version and the Version of Record. Please cite this article as an 'Accepted Article', doi: 10.1002/cne.24391 (c) 2018 Wiley Periodicals, Inc.

Received: Oct 11, 2017; Revised: Nov 30, 2017; Accepted: Dec 18, 2017 


\begin{abstract}
$(1)$

\section{Abstract}

Neurotrophins (NTF) are a family of secreted nerve growth factors with affinity for tyrosine kinase (Ntrk) and p75 receptors. To fully understand the variety of developmental roles played by NTFs, it is critical to know when and where genes encoding individual ligands and receptors are transcribed. Identification of $n t f$ and ntrk transcripts in zebrafish development remains to be fully characterized for further uncovering the potential function(s) of the NTF signal transduction pathway. Here, we conducted a systematic analysis of the expression profiles of four ntf and five ntrk genes during zebrafish development using whole-mount in situ hybridization. Our study unveils new expression domains in the developing embryo, confirms those previously known, and shows that $n t f$ and $n t r k$ genes have different degrees of cell- and tissue-type specificity. The unique and overlapping expression patterns here depicted indicate the coordination of the redundant and divergent functions of NTFs and represent valuable tools for deciphering the molecular pathways involved in the specification and function of embryonic cell types.
\end{abstract}

Key words: neurotrophins, neurotrophin tyrosine kinase receptors, zebrafish, development, phylogeny; RRID:SCR_008439 


\section{(1) \\ r \\ 1 INTRODUCTION}

The discovery of the neurotrophin family, structurally similar to nerve growth factors, was a seminal event in the history of research in neurobiology (reviewed in Aloe \& Calzà, 2004). At the cellular level, neurotrophins (NTFs) play fundamental roles in several aspects of developing and mature neural phenotypes, including proliferation, survival and synaptic plasticity in both the central and peripheral nervous systems (Chao, 2003; Antal et al., 2010). Because NTFs are thought to be involved in activity-dependent synaptic plasticity, there is great interest in their role in higher-order activities such as learning and memory (Yamada \& Nabeshima, 2003; Choi et al., 2010). There is growing evidence that reduced neurotrophic support is a significant factor in the pathogenesis of neurodegenerative diseases (Dawbarn \& Allen, 2003; Arancio \& Chao, 2007; Frade \& Lopez-Sanchez, 2010; Laske et al., 2011; Vilar \& Mira, 2016). An implication of NTFs in pathogenesis and treatment of neurological and psychiatric disorders has been proposed (Nagahara \& Tuszynski, 2011). Besides their action on neurons, new functions have been assigned to NTFs in several non-neural tissues including heart, lung, muscle, pancreas, adipose tissue, liver, vascular and the haemopoietic-immune system, providing insights into the way NTFs act in the embryo and in the adult (Oberg-Welsh \& Welsh 1996; Miralles, Philippe, Czernichow, \& Scharfmann, 1998; Teitelman, Guz, Ivkovic, \& Ehrlich, 1998; Larrieta, Vital, Mendoza-Rodríguez, Cerbon, \& Hiriart, 2006; Durand et al. 2007; Meloni et al., 2010). In particular, several data support the hypothesis that the immune/inflammatory system modulates NTFs through multiple mechanisms and that NTF expression may be involved in the differentiation of lymphoid and myeloid cell types (Calabrese et al., 2014; Minnone, De Benedetti, \& Bracci-Laudiero, 2017).

Mature NTF proteins exist as non-covalently associated dimeric polypeptides that are first synthetized as precursors and then cleaved to biologically active proteins (Chao \& Botwell, 2002). ProNTFs and mature NTFs can serve both autocrine and paracrine functions. NTFs undergo anterograde trafficking from the cell bodies through long axons (Baquet, Gorski, \& Jones, 2004) or, alternatively, target-derived factors may be transported retrogradely to distant cell bodies (Harrington \& Ginty, 2013; Ito \& Enomoto, 2016). NTFs mediate their action on responsive cells by binding to different receptors: all bind, both as proNTFs and 
as mature NTFs, to a common receptor $\mathrm{p} 75$, a member of the tumor necrosis factor receptor superfamily, and each mature protein also binds to one or more of the members belonging to neurotrophin tyrosine kinase receptors (Ntrk). NTF/Ntrk binding then exerts its functions by connecting a variety of intracellular signaling cascades, which include MAPK/ERK, PI-3/AKT kinase, and PLCY pathways (Nakagawara, 2001; Reichardt, 2006; Chalampopoulos et al., 2012).

Important achievements have been made in the understanding of NTF and NTF receptor evolutionary history: a functional NTF/Ntrk system was already present in bilaterian ancestor, predating the split between protostomes and deuterostomes, and secondarily lost in some clades like nematodes, insects and tunicates (Jaaro et al., 2001; BenitoGutiérrez et al., 2005; Benito-Gutiérrez, Garcia-Fernàndez, \& Comella, 2006; Bothwell, 2006; Burke et al., 2006; Lapraz et al., 2006; Wilson, 2009; Lauri, Bertucci, \& Arendt, 2016). The presence of one Ntf and one Ntrk gene in protostomes and in non-vertebrate chordates suggests that much of the complexity of the NTF/Ntrk system has evolved in the course of vertebrate radiation (Hallböök, Lundin, \& Kullander, 1998), likely as a result of whole-genome duplications (Ohno, 1993; Dehal \& Boore, 2005). The gnathostome genome typically include the nerve growth factors, NGF, BDNF, Ntf3, and Ntf5, and the three Ntrk receptors, NtrkA, NtrkB, and NtrkC (Cohen, Levi-Montalcini, \& Hamburger, 1954; Barde, Edgar, \& Thoenen, 1982; Hohn, Leibrock, Bailey, \& Barde, 1990; Berkemeier et al., 1991; Benito-Gutiérrez, Garcia-Fernàndez and Comella, 2006; Sossin, 2006), while birds have lost Ntf5 (Hallböök, Wilson, Thorndyke, \& Olinski, 2006). The additional wholegenome duplication which occurred in the common ancestor of teleosts (teleost-specific whole genome duplication, TSGD) (Taylor, Van de Peer, Braasch, \& Meyer, 2001; Taylor, Braasch, Frickey, Meyer, \& Van de Peer, 2003), was followed by lineage-specific gene losses, thus resulting in the presence of an additional fifth $n t f$ family member called $n t f 6$ or $n t f 7$, together with five Ntrk receptor coding genes, ntrk1, ntrk2a, ntrk2b, ntrk3a and ntrk3b (Heinrich \& Lum, 2000).

The zebrafish embryo is an attractive model for developmental biology and genetics of vertebrates for its conserved anatomy in terms of tissue formation and organization, including neuroectodermal derivatives such as brain and spinal cord. Despite zebrafish has undergone evolutionary changes, yet it is likely still bearing traits of the early expansion of the neurotrophin signaling system in vertebrates, thus representing a useful 
model for functional approaches and phenotypic characterization. In zebrafish, expression patterns of $b d n f, n t r k 2 b, n t r k 3 a$ and $n t r k 3 b$ were previously reported, while those of $n t f 4 / 5$ and $n t f 6 / 7$ are still unknown (Martin, Marazzi, Sandell, \& Heinrich, 1995; Martin, Sandell, \& Heinrich, 1998; Williams et al., 2000; Lum, Huynh, \& Heinrich, 2001; Thisse \& Thisse, 2004, 2005; Knaut et al., 2005; Thisse, Wright, \& Thisse, 2008; Tanaka et al., 2011; Pan et al., 2012; Morimura, Nozawa, Tanaka, \& Ohshima, 2013; Palanca et al., 2013; De Felice et al., 2014; Dyer, Linker, Graham, \& Knight, 2014; Auer et al., 2015). The current study was thus finalized at adding further insights into transcriptional activity of the whole complement of $n t f$ and $n t r k$ genes during zebrafish embryogenesis. The interpretation of our data is based on the anatomical and topographical distribution of ligand and receptor transcripts by whole-mount in situ hybridization method from 12 to 96 hours post fertilization (hpf). Furthermore, increasing availability of key fish genomes opens novel perspectives on the yet obscure evolution of ntrk genes. Here, we shed light on the phylogeny of neurotrophin tyrosine kinase receptors, which was deeply influenced by genome duplications and gene losses. Our approach, together with literature and genome browser data, prompted us to use a standardized nomenclature to indicate the genes of the NTF/Ntrk system.

\section{MATERIAL AND METHODS}

\subsection{Ntrk phylogenetic analysis}

Ntrk predicted amino acid sequences used in our evolutionary reconstruction were retrieved from public databases and aligned using Clustal Omega (Sievers et al., 2012). We included Ntrk proteins from selected species based on their key phylogenetic position and genome features. Ntrk sequences from Homo sapiens (Hs_NTRK1: NP_001012331; Hs_NTRK2: ENSP00000365386; Hs_NTRK3: ENSP00000377990) and Danio rerio (Dr_Ntrk1: NP_001288285; Dr_Ntrk2a: NP_003199193_2, Dr_Ntrk2b: XP_001184090; Dr_Ntrk3a: XP_005163050; Dr_Ntrk3b: XP_002662799 - here manually implemented) were retrieved from NCBI and Ensembl. The set of proteins was enriched by the search of novel sequences from the West Indian Ocean coelacanth, Latimeria chalumnae (Lc_Ntrk1: ENSLACP00000017880; Lc_Ntrk2: ENSLACP00000003030), the Australian ghost shark, 
Callorhinchus milii (Cm_Ntrk2: XP_007904999; Cm_Ntrk3: XP_007908653), and the spotted gar, Lepisosteus oculatus (Lo_Ntrk1: XP_006643007; Lo_Ntrk2: ENSLOCP00000002703; Lo_Ntrk3: ENSLOCP00000017879). Phylogenetic trees were inferred using MrBayes 3.1.2 generated with default parameters: two independent runs of $1,000,000$ generations were performed, each with 4 chains. The single amphioxus Ntrk receptor Branchiostoma floridae (AAX94285), representative of the invertebrates' preduplicative gene, was used as outgroup (D’Aniello et al., 2008).

\subsection{Embryos}

Adult zebrafish (Danio rerio) were maintained according to standard procedures on a $14 \mathrm{~h}$ light $/ 10 \mathrm{~h}$ dark lighting cycle at $28.5^{\circ} \mathrm{C}$ as previously described (Westerfield, 2000). Embryos were obtained by natural spawning, and were staged according to hours and days post-fertilization (hpf and dpf, respectively), and to morphological criteria (Kimmel, Ballard, Kimmel, Ullmann, \& Schilling, 1995). At $22 \mathrm{hpf}$, the embryo medium was supplemented with $0.003 \%(\mathrm{v} / \mathrm{v})$ phenylthiourea to inhibit melanin synthesis.

\subsection{Whole-mount in situ hybridization and immunohistochemistry}

For each gene (ngf, ntf3, ntf4/5, ntf6/7, ntrk1, ntrk2a, ntrk2b, ntrk3a, and ntrk3b) we generated digoxigenin-labeled sense and antisense riboprobes, ranging in length from 267 to 1117 nucleotides, to enable us to gain a view on the expression of nearly all alternative transcripts (Supporting Fig. 1, Supporting Tab. 1). Single and double whole-mount in situ hybridization (WISH) analyses were performed as previously described (Westerfield, 2000). Embryos were post-fixed in 4\% paraformaldehyde (PFA) in 1X phosphate-buffered saline (PBS) for $20 \mathrm{~min}$ and finally stored in $95 \%$ glycerol at $4^{\circ} \mathrm{C}$ until use. Embryos were imaged using a Zeiss Axio Imager M1 microscope equipped with Axiocam digital camera (Zeiss). WISH experiments were conducted in triplicate with consistent results. No signal was observed with the sense riboprobes, indicating the specificity of the antisense riboprobes generated (data not shown). For ntf3, after the in situ hybridization experiments, $72 \mathrm{hpf}$ embryos were embedded in a mix of BSA and gelatin and sectioned with vibratome at a thickness of $20 \mu \mathrm{m}$.

Double-fluorescent WISH was performed following the protocol of Brend and Holley, 2009. Embryos were fixed overnight at $4^{\circ} \mathrm{C}$ using $4 \%$ PFA in PBS, then washed with PBS, 
transferred through a series of 25\%, 50\%, 75\% methanol in PBS and incubated in 100\% methanol at $-20^{\circ} \mathrm{C}$. Embryos were rehydrated in $75 \%, 50 \%, 25 \%$ methanol in PBSTween20 (PBST) at RT, washed in PBST, fixed again for $20 \mathrm{~min}$ in 4\% PFA in PBS at RT and washed 2 times in PBST. Prim-5 stage embryos were permeabilized by treatment with proteinase $\mathrm{K}(10 \mu \mathrm{g} / \mathrm{ml}$ in PBST) at RT for $5 \mathrm{~min}$. After brief washes in PBST to stop the reaction, embryos were fixed again for $20 \mathrm{~min}$ in 4\% PFA in PBS at RT. Then they were incubated for $5 \mathrm{~min}$ at $65^{\circ} \mathrm{C}$ in $\mathrm{HYB}^{-}$buffer $(50 \%$ deionized formamide, $5 \mathrm{x}$ SSC, $0.1 \%$ Tween20) and prehybridized at $65^{\circ} \mathrm{C}$ for at least 1 hour in $\mathrm{HYB}^{+}\left(\mathrm{Hyb}^{-}, 500 \mu \mathrm{g} / \mathrm{ml}\right.$ yeast

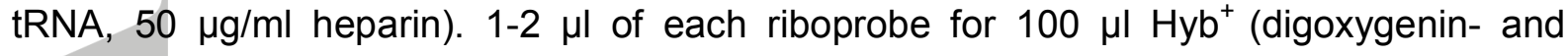
fluorescein-labeled riboprobes) were added to the embryos and incubated overnight at $65^{\circ} \mathrm{C}$. After riboprobe incubation, embryos were washed $3 \times 30 \mathrm{~min}$ at $65^{\circ} \mathrm{C}$ in $50 \%$ formamide/2x SSC, $3 \times 15$ minutes at $65^{\circ} \mathrm{C}$ in $2 \times \mathrm{SSC}$, and $2 \times 30$ minutes at $65^{\circ} \mathrm{C}$ in $0.2 \mathrm{x}$ SSC. The embryos were blocked for at least 1 hour at RT in $500 \mu$ of a solution of $1 x$ maleic acid buffer plus $2 \%$ blocking reagent (Roche). The anti-Fluorescein-POD antibody (Roche), was added at a 1:400 dilution in the blocking solution and incubated overnight at $4^{\circ} \mathrm{C}$. After incubation, we washed $4 \times 20$ minutes in $1 \times$ maleic acid buffer and twice for 5 minutes each in PBS, and then incubated 60 minutes in Perkin Elmer amplification diluent buffer (TSA ${ }^{\text {TM }}$ Plus Cyanine 3 \& Cyanine 5 System Perkin Elmer). For the reaction, we diluted AlexaFluor647 reagent (TSA ${ }^{\text {TM }}$ Reagent, Alexa Fluor ${ }^{\circledR} 647$ Tyramide, Life Technologies) 1:100 in Perkin Elmer amplification diluent buffer. After, we washed for 10 minutes each in 25\%,50\%,75\% and $100 \%$ methanol in PBS, incubated in a solution of $1 \% \mathrm{H}_{2} \mathrm{O}_{2}$ in methanol for 30 minutes to inactivate endogenous peroxidases, and washed again 10 minutes each in 75\%, 50\%, 25\% methanol in PBS, and $3 \times 10$ minutes in PBS. Embryos were blocked again for at least 1 hour at RT in a solution of $1 \mathrm{x}$ maleic acid buffer plus $2 \%$ blocking reagent. The anti-DIG POD antibody (Roche) was added at a 1:400 dilution in above blocking solution and embryos were incubated overnight at $4^{\circ} \mathrm{C}$. Embryos were washed $4 \times 20$ minutes in 1x maleic acid buffer, $4 \times 10$ minutes in PBS and incubated 60 minutes in Perkin Elmer amplification diluent buffer. For the reaction, we diluted Cy3 tyramide reagent 1:100 in amplification buffer, after we washed three times for 10 minutes each and then overnight in PBST. Finally, the embryos were incubated for 10 minutes in $25 \%$ and $50 \%$ glycerol in PBST and cleared overnight in $75 \%$ glycerol at $4^{\circ} \mathrm{C}$. Wholemount fluorescent zebrafish preparations mounted on slides were imaged on a Zeiss LSM 
700 laser scanning confocal microscope with 10x or 20x objective with 1x zoom. Excitation and emission wavelengths were set according to the fluorophore used. Pictures were edited with Adobe Photoshop CS4.

\section{RESULTS}

\subsection{Ntrk phylogenetic reconstruction}

The evolutionary history of NTFs in vertebrates is substantially well defined, due to the presence of a single representative of each NTF family member in all species considered. On the contrary, the evolutionary outline of Ntrk receptors is made more complex by gene redundancy (Hallböök et al., 2006; Sossin, 2006; Lanave, Colangelo, Saccone, \& Alberghina, 2007; D'Aniello et al., 2008; Tettamanti et al., 2010). Literature data suggest that the unique invertebrate Ntrk represents the pre-duplicative ancestor of the three duplicates found in vertebrates. Therefore, we performed a phylogenetic reconstruction to better define the evolutionary history of Ntrk receptors (Fig. 1). In particular, the phylogenetic relationship between the duplicated Ntrk2 and Ntrk3 genes of sarcopterygian lineage (comprising human) and actinopterygians (two ray-finned fish) remains obscure. For this purpose, in the analysis we included the spotted gar Lepisosteus oculatus as representative of unduplicated Actinopterygii, which has a single ntrk gene for each clade, like tetrapods as human. We also included the coelacanth Latimeria chalumnae, and the ghost shark, Callorhinchus milii, that possess two ntrk genes, according to current available genomic data (Venkatesh et al., 2014). Our analysis points to the three genes present in vertebrates (Ntrk1, Ntrk2, Ntrk3) as descendants of a unique invertebrate ancestor, as a result of the WGDs occurred at the stem of vertebrates (Ohno, 1993; Dehal and Boore, 2005). Moreover, it is parsimonious that teleost ntrk2a-ntrk2b and ntrk3a$n t r k 3 b$ genes are couples of ohnologs arisen by TSGD (Taylor, Van de Peer, Braasch, \& Meyer, 2001; Taylor, Braasch, Frickey, Meyer, \& Van de Peer, 2003), while a single copy gene of Ntrk1 in all surveyed gnathostome species would suggest that a second Ntrk1 paralogue has been lost across evolution. Noteworthy, ntrk1 and ntrk3 resulted lost in $C$. milii and L. chalumnae, respectively (Fig. 1). It would be important in future to understand the molecular implications of the modification of NTF family in fishes according to their 
specific ecological niche.

\subsection{Nomenclature}

There is currently considerable confusion concerning the acronyms indicating neurotrophins and their tyrosine kinase receptors. Whereas BDNF and NGF are known with these names in all vertebrates, other neurotrophin pathway genes are indicated with multiple acronyms in different species. The fact that different NTF names are used in distinct species is misleading for evolutionary and comparative studies that, for instance, aim to find similarity or novelties using a cross-lineage approach. The absence of a univocal nomenclature used by different animal models in research communities is particularly evident in the case of human or mouse in respect to teleost fishes. Phylogenetic reconstructions assessed with limited dataset, or gene name attributions incoherent with the orthology principle, may hinder direct transfer of morphological and functional information from teleost fishes to human. To mention some examples, one gene is named $n t f 4$ in zebrafish (Auer et al., 2015), NT-4/5 in mice (English, Cucoranu, Mulligan, Rodriguez, \& Sabatier, 2011), NT4 in rat (Proenca, Song, \& Lee, 2016) and NT5 in human (Berkemeier, Ozçelik, Francke, \& Rosenthal, 1992). Therefore, hereon we will indicate this gene as $N t f 4 / 5$ in mammals and $n t f 4 / 5$ in fish. Similarly, NT-6 in platyfish (Gotz et al., 1994 ) is named NT-7 in zebrafish (Nilsson, Fainzilber, Falck, \& Ibanez, 1998), and hereon we name it $n t f 6 / 7$. Of note, genome databases (e.g. MGI, NCBI, HGNC) have recently (November 2017) approved Ntrk1, Ntrk2 and Ntrk3 as new symbols for mammalian TrkA, TrkB and TrkC proteins. Here we refer to the zebrafish genes bdnf, ngf, ntf3, ntf4/5, ntf6/7, ntrk1, ntrk2a, ntrk2b, ntrk3a and ntrk3b.

\subsection{Expression patterns}

\subsubsection{Ligands}

3.3.1.1 $\mathrm{ngf}$. As reported previously in the context of a large scale whole-mount in situ hybridization screening, zebrafish $n g f$ is expressed in the epidermis surrounding anteriorly the neural plate during early somitogenesis (12 hpf) (Thisse \& Thisse, 2004; 2005). Most optic tectum cells appeared to be labeled strongly at $24 \mathrm{hpf}$ (Fig. 2a,a'). Positive cells were also observed in the ventral margin of the otic vesicle, in a small cluster of head mesenchymal cells within the pharyngeal arches, in lateral line primordium and 
posteriormost somites (Fig. 2a,b). At 36 hpf, ngf expression ceased in the optic tectum and caudal somites, and became intense in pharyngeal arches, neurons within the trigeminal ganglion and posterior pharynx (Fig. 2c,d). At 48 hpf, expression persisted in the lower jaw structures, likely including the ventral oral epithelium and paired ceratobranchials, and in the posterior pharynx (Fig. 2e,f). No expression was observed at later stages (data not shown).

3.3.1.2 ntf3: The transcriptional anatomy of $n t f 3$ during zebrafish development is very peculiar in terms of tissue specificity when compared with the other neurotrophin genes. Like $n g f, n t f 3$ expression was activated at the early somitogenesis stage (12 hpf) in the epidermis along the neural plate border, in cardiac progenitor cells and in the lateral line primordium (Fig. 3a). At 22 hpf, ntf3 positive cells were observed in the linear heart tube, otic vesicle, lateral line primordium, pancreas and posterior somites (Fig. 3b,c). Williams and co-authors (2000) showed that $n t f 3$ is important for Rohon-Beard (RB) neuron development in zebrafish. During our experiments, no sign of $n t f 3$ expression was detected in the spinal cord (Fig. 3b,c). At 48 hpf, cells expressing ntf3 were present in the central retina, pituitary gland and pancreas (Fig. 3d,e,g). No more expression was detected in lateral line and inner ear, while the cardiac signal remained ubiquitous (Fig. $3 \mathrm{~d}, \mathrm{e})$. At $72 \mathrm{hpf}$, discrete bilateral groups of neuronal cell types expressing $n t f 3$ were observed in the brain and cranial nerve region (Fig. 3f). Expression in the retina had spread from central to peripheral photoreceptors (Fig. 3g-j) and to the inner nuclear layer in the temporal retina (Fig. 3h,k). No expression was seen at later stages (data not shown).

3.3.1.3 ntf4/5: The only information available in literature concerning the embryonic expression in zebrafish of this neurotrophin coding gene consists on transcriptional levels measured by RT-qPCR at $4 \mathrm{dpf}$ (Auer et al., 2015). In our investigations, the first expression of $n t f 4 / 5$ was found in the posterior epiblast during early somitogenesis (12 hpf) (Fig. 4a-c). At $24 \mathrm{hpf}$, mRNA staining occurred in cranial nerves, lateral line primordium and in the median finfold surrounding the tail (Fig. 4d,e). At $48 \mathrm{hpf}$, positive cells formed columns that were arranged around the pharyngeal arch region (Fig. 4f,g). This signal was 
confined to the anterior most group of pharyngeal cells at $72 \mathrm{hpf}$ (Fig. 4h). Finally, a strong signal labeled the inner wall of the intestine bulb at 96 hpf (Fig. 4i,j).

3.3.1.4 $n t f 6 / 7$ : The fish lineage-specific neurotrophin $n t f 6 / 7$ was originally identified in the platyfish, Xiphophorus maculatum (Gotz et al., 1994). Based on our knowledge of the literature, no whole-mount expression study of $n t f 6 / 7$ has so far been conducted in any fish species. Its developmental expression in zebrafish is unique because it was restricted to the otic vesicle (OV). Early transcript was detected at $16 \mathrm{hpf}$ in two clusters of cells adjacent to the anterior and posterior of the inner ear primordium (16 hpf) (Fig. 4k,I). As development proceeds, $n t f 6 / 7$ expression was extended in 3-4 small sensory OV patches at 24 and 48 hpf (Fig. 4m-o). Expression was lost at later stages (data not shown).

\subsubsection{Receptors}

3.3.2.1 ntrk1: In spite of teleost-specific third whole genome duplication (Taylor, Van de Peer, Braasch, \& Meyer, 2001; Taylor, Braasch, Frickey, Meyer, \& Van de Peer, 2003), the zebrafish genome contains only one ntrk1 gene, which could be explained by a specific gene loss (Heinrich \& Lum, 2000). At 24 hpf, the zebrafish ntrk1 was expressed in two domains of cranial nerve ganglia flanking the hindbrain: a large and a small group anterior and posterior to the otic vesicle, respectively (Fig. 5a,b). The ntrk1 transcript was detected in RB neurons localized in the dorsal aspect of the spinal cord (Fig. $5 \mathrm{c}$ ). At 48 and $72 \mathrm{hpf}$, ntrk1-positive cells were similarly distributed as they were seen in two columns projecting toward the eye in the ventral head mesenchyme, and in trigeminal sensory neuron subtypes (Knaut, Blader, Strähle, \& Schier, 2005; Tanaka et al., 2011; Pan, Choy, Prober, \& Schier, 2012; Palanca et al., 2013) (Fig. 5d-f). Cells expressing ntrk1 were found at the base of the pectoral fins, suggesting a correspondence to pectoral motor nerve ganglia (Fig. 5d-f). No spinal cord labeling was detected at this stage (data not shown). At $6 \mathrm{dpf}$, ntrk1 was expressed in the trigeminal ganglion and in the rostral hindbrain (Martin, Marazzi, Sandell, \& Heinrich, 1995).

3.3.2.2 ntrk2a: The expression of the ntrk2a gene in the trigeminal ganglia and RB neurons has been previously described (Martin, Marazzi, Sandell, \& Heinrich, 1995; Palanca et al., 2013). Here, we observed hypoblast labeling throughout the embryo at 
early somitogenesis stage (12 hpf) (Fig. 6a). At 24 hpf, ntrk2a transcription occurred in discrete groups of neuronal cell types in the posterior telencephalon, hypothalamus, ventral thalamus, ventral tegmentum, ventral hindbrain, cranial ganglia and spinal cord (Fig. 6b-d). Cells expressing ntrk2a in the spinal cord are RB neurons localized dorsally, as well as ventral cells that may represent motoneurons or interneurons (Fig. 6d). At 48 hpf, ntrk2a mRNA marked the brain, with new signals appearing in trigeminal ganglion and ganglion cell layer (GCL) (Fig. 6e,f). The cerebral signal was still diffuse at the stage of 96 hpf, when strong staining was found in the pharyngeal epithelium (Fig. 6g).

3.3.2.3 ntrk2b: At $12 \mathrm{hpf}$ (6 somite stage), ntrk2b mRNA was evenly localized in the anterior half of the embryo (Fig. 6h). In agreement with earlier findings (Thisse, Wright, \& Thisse, 2008), ntrk2b was expressed in posterior telencephalon, ventrorostral thalamus, ventral tegmentum and ventral hindbrain at $24 \mathrm{hpf}$ (Fig. 6i,j). Hybridization staining was spread in the brain at $48 \mathrm{hpf}$, when a new expression domain appeared in the ganglion cell layer (Fig. 7k,I). The cerebral signal was still diffuse at 96 hpf (Fig. 6m).

3.3.2.4 ntrk3a: The available evidence with regard to the expression of ntrk3a in the brain of 24 hpf embryo included several subsets of neuroanatomical domains (Martin, Sandell, \& Heinrich, 1998; Pan, Choy, Prober, \& Schier, 2012; Morimura, Nozawa, Tanaka, \& Ohshima, 2013; Dyer, Linker, Graham, \& Knight, 2014; Auer et al., 2015). In particular, groups of ntrk3a mRNA-positive cells were found in the telencephalon, pituitary gland, posterior hypothalamus, ventrorostral thalamus, posterior hindbrain, cranial ganglia, otic vesicle and RB neurons (Fig. 7a-C). Contrary to previous evidence, ntrk3a was undetectable in the trigeminal ganglia (Pan, Choy, Prober, \& Schier, 2012). With some exceptions, ntrk3a mRNA pattern is very similar with that of ntrk2a (compare Fig. 6b \& Fig. 7a), and even more with that of bdnf (De Felice et al., 2014). At later developmental stages, ntrk3a expression occurred in pectoral motor nerve ganglia (48 hpf) and diffusely in the brain (48 to 96 hpf) (Fig. 7d-f).

3.3.2.5 ntrk3b: At $24 \mathrm{hpf}$, the expression of the ntrk3b gene was confined to small groups of neural cell types in the telencephalon, ventral thalamus, ventral tegmentum and anterior margin of the otic vesicle (Fig. $7 g-i)$. This pattern was reminiscent of $n t r k 2 b$ transcript 
distribution at same stage (compare Fig. 6i \& Fig. 7g), raising the possibility of functional redundancy between $n t r k 2 b$ and $n t r k 3 b$. At $48 \mathrm{hpf}, n t r k 3 b$ expression was switched on in the olfactory placode, GCL and hindbrain, while it persisted in diencephalon and midbrain (Fig. 7j,k). Finally, ntrk3b transcription was detected across the brain at $96 \mathrm{hpf}$ (Fig. 7l). Both ntrk3a and ntrk3b_were expressed in the GCL at 6 dpf (Auer et al., 2015).

3.3.2.6 bdnf and ntrk2a co-localization: Based on the expression patterns of zebrafish ntf and ntrk genes, ligands and receptors could be co-expressed in several subregions of the neural and sensory systems during ìbrain development. In support of this hypothesis, our data indicate that the expression pattern of ntrk2a was very similar to that of bdnf (compare Fig. 6b and Fig. 2b in De Felice et al., 2014). We thus performed double in situ hybridizations of bdnf and its specialized ntrk2a receptor at $24 \mathrm{hpf}$. As expected, fluorescent imaging of transcripts showed co-labeling in cranial nerves but not in RB neurons (Fig. 8).

\section{DISCUSSION}

\subsection{Phylogenetic reconstruction}

Our phylogeny reveals that, differently from NTFs, Ntrk receptors exhibit a complex evolutionary history. Genome duplication events expanded the gene complement in vertebrates, giving rise to three receptor genes (Ntrk1, Ntrk2, Ntrk3) in tetrapods and five in teleosts (ntrk1, ntrk2a, ntrk2b, ntrk3a, ntrk3b). Independent gene losses have sculpted the modern scenario in which gnathostomes lack a fourth Ntrk member and teleosts lost a ntrk1 duplicate. We have registered other cases of ntrk gene loss in holocephalans and early-branching actinopterygians. This phenomenon could be correlated with gene subfunctionalization or, more intriguingly, with evolutionary innovations (Albalat \& Cañestro, 2016).

\subsection{Expression patterns}

We used the zebrafish to provide the first comprehensive examination of the expression profiles of neurotrophins and neurotrophin tyrosine kinase receptors in vertebrates (Fig. 9, 
Supporting Table 2). Previous findings highlighted the presence of five ntf and five ntrk receptor genes in the zebrafish genome, but offered incomplete understanding of the transcriptional anatomy during early development. In addition, ntf4/5 and ntf6/7 were hitherto not described in terms of expression domains in fish embryo development. Our global survey shows that nearly all patterns of $n t f$ and $n t r k$ genes exhibit restricted mRNA domains and are expressed in unique combinations, reflecting qualitative differences between tissues and organs. Considering that NTFs have stereotypical cellular functions, their anatomical distribution in zebrafish reveals the physiological and cell biological state in the embryo during development.

\subsubsection{Expression of ntf and ntrk genes in neural and sensory systems of zebrafish embryos}

The results described here hint at bdnf as the only neurotrophin gene whose transcription is extensively associated with early neurogenesis in zebrafish. Based on ligand and receptor transcripts co-localization (Supporting Table 2), a potential role may be ascribed to zebrafish Bdnf protein in the development of neurons devoted to a variety of functions and behaviours (this work; Lagler, Bardach, \& Miller, 1967; Eaton \& Whittemore, 1996; De Felice et al., 2014). As suggested by comparative analysis of expression patterns, Bdnf could exert these various roles by activating its specialized receptor, Ntrk2, but also Ntrk3 (Fig. 9; Supporting Table 2). Similarly, Ngf could bind to both Ntrk1 and Ntrk2a, given its unique expression in optic tectum and trigeminal cell bodies, lending support to a neurotrophic role in the development of neural circuits involved in visually guided behaviour and in sensory coding of environmental stimuli (Robles, Smith, \& Baier, 2011; reviewed in Pan, Choy, Prober, \& Schier, 2012).

One of the most interesting observations we have made is that, differently from tetrapods, $b d n f$ is the only neurotrophin gene expressed in the telencephalon of the zebrafish embryo (Fig. 9, Supporting Table 2). In the classical view of telencephalic evolution, the dorsal pallium of fish has acutely expanded, becoming the isocortex of mammals. This enlargement has paralleled the acquisition of increased complexity in learning and behaviour processes in man (Rowe, Macrini, \& Luo, 2011; Mueller, 2012). It is tempting to speculate that expansion of the neurotrophin signaling system, with the activation of ngf, $n t f 3$ and $n t f 4 / 5$ expression in the isocortex, was one of the enabling conditions in the 
evolution of complex brains (Lauterborne, Isackson, \& Gall, 1994; Brunstrom, Gray-Swain, Osborne, \& Pearlman, 1997; Jaaro, Beck, Conticello, \& Fainzilber, 2001; Jaaro \& Fainzilber, 2006). In this view, the abundance of nerve growth factors in integrative centers could have represented the basis for giving rise to higher cognitive functions.

Previous studies indicated that the NTF pathway is highly implicated in the development of neuronal and sensory cell types in the peripheral nervous system. The presence of ntrk (ntrk1, ntrk2a, ntrk3a) gene transcripts in RB neurons, in the absence of NTF gene expression (Fig. 9, Supporting Table 2), could reflect a long-range anterograde NTF axonal transport (Martin, Sandell, \& Heinrich, 1998; Williams et al., 2000; Knaut et al., 2005; Pan, Choy, Prober, \& Schier, 2012; Tanaka et al., 2011; Morimura, Nozawa, Tanaka, \& Ohshima, 2013; Palanca et al., 2013; Dyer, Linker, Graham, \& Knight, 2014; Auer et al., 2015). We cannot exclude that Ntrk proteins in the spinal cord of the zebrafish embryo are transactivated by alternate ligands without involvement of neurotrophins, e.g. via a mechanism based on G-protein-coupled receptor ligands (Daub, Weiss, Wallasch, \& Ullrich, 1999; Lee et al., 2001; Rajagopal, Chen, Lee, \& Chao, 2004; Kim et al., 2016). Long-distance or alternative signaling mechanisms may also support ntrk3a and ntf3 expression in pineal and pituitary glands, respectively.

The auditory system of vertebrates is composed of the inner ear and the mechanosensory lateral line system (Gasanov, Rafieva, \& Korzh, 2015). Intriguingly, transcripts of three neurotrophins (bdnf, ngf, ntf6/7) and two receptors (ntrk3a, ntrk3b) were detected in the otic vesicle (Fig. 9, Supporting Table 2), an anatomical structure that develops into the auditory (hearing) and vestibular (balance) organ of the fish, equivalent to the inner ear of amniotes. In addition, we found that $n t f 3$ and $n t f 4 / 5$, like bdnf and ngf (Germanà et al., 2010; De Felice et al., 2014), are expressed in the lateral line primordium. Collectively, our results highlight the potential role of the NTF pathway in the development of the otic vesicle, and indicate the existence of a complex neurotrophin mechanism involved in migration and maintenance of mechanosensory progenitors (Grave et al., 2013; Gasanov, Rafieva, \& Korzh, 2015).

The role of BDNF and NTF3 in retinal neurorestoration, neuroprotection and oxidative stress has been extensively tested over the past two decades. Responsiveness of the ganglion cell layer to neurotrophins coincides with terminal arborisation and patterning of retinal axons (Cohen-Cory \& Fraser, 1994; Logan, Ahmed, Baird, Gonzalez, \& Berry, 
2006; Hackam, 2008; Liu et al., 2009; Santos et al., 2011). Based on results from a previous study, zebrafish Ntf3 controls axon branching in the retinotectal system (Auer et al., 2015). In our work, NTF role in the developing retina of zebrafish appears to be genetically conserved with reference to mammalian retina, with the transcriptional activation of bdnf, ntrk2a, ntrk $2 b$ and $n t r k 3 b$ in the ganglion cell layer, and of $n t f 3$ in the photoreceptor cell layer (this work; Hallböök, Bäckström, Kullander, Ebendal, \& Carri, 1996; De Felice et al., 2014; Garcia, Hollborn, \& Bringmann, 2017). During retina neurogenesis, the expression of bdnf and $n t f 3$ expands in opposing directions and coincides in the inner nuclear layer (this work; De Felice et al., 2014). Concerted expression of these two zebrafish NTFs may play an important role in the differentiation and maintenance of multiple retinal cell types. In addition, it evokes that Bdnf and Ntf3 anterograde signaling in ganglion cell layer is mediated by Ntrk receptors, and it is temporally regulated (Butowt \& von Bartheld, 2005). Also, late activation of bdnf and ntf3 genes in the retina argues against a role in cell proliferation.

\subsubsection{Non-neuronal roles for zebrafish neurotrophins}

In the present study, the spatial expression of $n t f$ and ntrk genes supports previous findings in zebrafish that imply differential functions in brain development. It also provides additional information on non-neural activities about which little is known (Tessarollo, 1998). NTFs have important functions in the development and physiology of mesoderm and endoderm, with particular combinations of NTFs and Ntrk receptors that these cells express.

BDNF and NTF3 participate in cardiac development regulating embryonic cardiomyocyte proliferation and intramyocardial vessel stabilization in mammals (Donovan, Hahn, Tessarollo, \& Hempstead, 1996; Donovan et al., 2000; Tessarollo et al., 1997; Lin et al., 2000; Feng et al., 2015), a function that is mediated by the expression of truncated Ntrk2 receptor (Fulgenzi et al., 2015). We have previously shown that zebrafish bdnf is transiently expressed in cardiac cell progenitors (De Felice et al., 2014). Here, ntf3 mRNA was seen across the whole zebrafish heart field at $24 \mathrm{hpf}$ and $48 \mathrm{hpf}$. Conversely, no ntrk gene expression was switched on in the heart during zebrafish embryogenesis (this work; Hannestad et al., 2000). 
The pancreas is a complex organ formed by endocrine islet cells that secrete insulin and glucagon, exocrine cells that secrete digestive enzymes, and a ductal network. In addition, while intrapancreatic blood vessels assure hormone circulation, a pancreas-specific nervous system consisting of ganglia and nerves participate in the regulation of insulin secretion and blood glucose homeostasis (Salvioli et al., 2002; Houtz, Borden, Ceasrine, Minichiello, \& Kuruvilla, 2016). In mammals, the classical neurotrophin NGF regulates $\beta$ cell survival and function, and there is evidence that altered NTF secretion could contribute to diabetes (Kim et al., 2009). The present study shows that, in zebrafish, the only $n t f$ gene to be robustly expressed in pancreatic endocrine cells is $n t f 3$, whereas its mammalian ortholog is weakly expressed in the pancreatic islet cells (Ohta et al., 1997; Miralles, Philippe, Czernichow, \& Scharfmann, 1998). Besides no evidence of ntrk receptor expression in the glandular organ has been collected so far in zebrafish, our findings are consistent with an important role in the development of the pancreas for Ntf3.

In mammalian digestive system, NTF4/5 is thought to be required for proper intestinal sensory innervation (Fox et al., 2001), a role that seems to be conserved in teleosts, as suggested by zebrafish $n t f 4 / 5$ expression in the intestinal bulb of the midgut. Noteworthy, ntrk transcripts are undetected in gastrointestinal progenitor cells at any developmental stage under scrutiny. The absence of ntrk gene expression in non-neural tissues was already reported by Martin and coauthors (1995), who used radioactive riboprobe-based in situ hybridization of sections of $4 \mathrm{dpf}$ zebrafish larvae. Evidence that $p 75 a$ and $p 75 b$ ohnologous genes are not transcribed in non-neural tissues of zebrafish embryos (Brösamle \& Halpern 2009; Han et al., 2014) extends to mesoderm and endoderm anlagen the view that zebrafish neurotrophins function by activating Ntrk receptors via long-distance signaling or through different local receptors.

\subsubsection{Conclusions}

Within vertebrates, whole-genome duplications led to multiple gene copies of neurotrophins and neurotrophin tyrosine kinase receptors. This duplicative pattern allowed the evolution of novel functions and pleiotropic effects, most of which still unknown, produced by the different associations of NTFs and their ligands in the nervous system. Our work, aimed at defining the precise expression domains of each NTF family member during zebrafish development, is just framed in the perspective of gaining information 
about the structure of molecular interactions, thus providing a canvas for targeted functional studies (Fig. 9). This complete developmental profiling indicates differential functions in different regions, offering novel routes for investigations into the biological role of each individual NTF as well as for the study of their combinatorial interaction with neurotrophin receptor tyrosine kinases.

\section{CONFLICT OF INTEREST}

The authors declare that they have no conflicts of interest.

\section{AUTHOR CONTRIBUTIONS}

All authors had full access to all the data in the present study and certify the integrity of the data and the accuracy of data analysis and interpretation. V.N., R.M.S., U.C., Y.D.A. E.D.F., A.P., Q.A.V., P.S. and S.D.A. led the experimental part and acquired the data. P.S. wrote the majority of the article, further completed by all authors; V.N., A.L., P.S., F.R. and S.D.A. led the figure and table preparation. All authors approved the article.

\section{REFERENCES}

Albalat, R., \& Cañestro, C. (2016). Evolution by gene loss. Nat Rev Genet, 7, 379-391.

Aloe, L., \& Calzà, L. (2004). NGF and related molecules in health and disease. Progr Brain Res, $146,1.544$.

Antal, A., Chaieb, L., Moliadze, V., Monte-Silva, K., Poreisz, C., ... Paulus, W. (2010). Brain-derived neurotrophic factor (BDNF) gene polymorphisms shape cortical plasticity in humans. Brain Stimul, 3, 230-237.

Arancio, O., \& Chao, M. V. (2007). Neurotrophins, synaptic plasticity and dementia. Curr Opin Neurobiol, 17, 325-30. 


\section{$(1)$}

Auer, T. O., Xiao, T., Bercier, V., Gebhardt, C., Duroure, K., ... Del Bene, F. (2015). Deletion of a kinesin I motor unmasks a mechanism of homeostatic branching control by neurotrophin-3. eLife, 4.

Baquet Z. C., Gorski J. A., \& Jones, K. R. (2004). Early striatal dendrite deficits followed by neuron loss with advanced age in the absence of anterograde cortical brain-derived neurotrophic factor. J Neurosci, 24, 4250-4258.

Barde, Y. A., Edgar, D., \& Thoenen, H. (1982). Purification of a new neurotrophic factor from mammalian brain. EMBO J, 1, 549-553.

Benito-Gutiérrez, E., Nake, C., Llovera, M., Comella, J., \& Garcia-Fernàndez, J. (2005).

The single AmphiTrk receptor highlights increased complexity of neurotrophin signalling in vertebrates and suggests an early role in developing sensory neuroepidermal cells. Development, 132, 2191-2202.

Benito-Gutiérrez, E., Garcia-Fernàndez, J., \& Comella, J. (2006). Origin and evolution of the Trk family of neurotrophic receptors. Mol Cell Neurosci, 31, 179-192.

Berkemeier, L. R., Ozçelik, T., Francke, U., \& Rosenthal, A. (1992). Human chromosome 19 contains the neurotrophin- 5 gene locus and three related genes that may encode novel acidic neurotrophins. Somat Cell Mol Genet, 18, 233-245.

Berkemeier, L. R., Winslow, J. W., Kaplan, D. R., Nikolics, K., Goeddel, D. V., \& Rosenthal, A. (1991). Neurotrophin-5: a novel neurotrophic factor that activates trk and trkB. Neuron 7, 857-866.

Brend, T., \& Holley, S. A. (2009). Zebrafish whole mount high resolution double fluorescent in situ hybridization. J Vis Exp, 25, 1229. 
Brösamle, C., \& Halpern, M. E. (2009). Nogo-Nogo receptor signalling in PNS axon outgrowth and pathfinding. Mol Cell Neurosci, 40, 401-409.

Brunstrom, J. E., Gray-Swain, M., R., Osborne, P. A., \& Pearlman, A., L. (1997). Neuronal heterotopias in the developing cerebral cortex produced by neurotrophin-4. Neuron, 18. 505-517.

Burke, R., Angerer, L., Elphick, M., Humphrey, G., Yaguchi, S., ... Thorndyke, M. C. (2006). A genomic view of the sea urchin nervous system. Dev Biol, 300, 434-460.

Butowt, R., \& von Bartheld, C. S. (2005). Anterograde axonal transport of BDNF and NT-3 by retinal ganglion cells: roles of neurotrophin receptors. Mol Cell Neurosci, 29, 11-25.

Calabrese, F., Rossetti, A. C., Racagni, G., Gass, P., Riva, M., \& Molteni, R. (2014) Brainderived neurotrophic factor: a bridge between inflammation and neuroplasticity. Front Cell Neurosci, 8, 430.

Chao, M. V. (2003). Neurotrophins and their receptors: a convergence point for many signalling pathways. Nat Rev Neurosci, 4, 299-309.

Chao, M. V., \& Bothwell, M. (2002). Neurotrophins: to cleave or not to cleave. Neuron, 33, $9-12$.

Charalampopoulos, I., Vicario, A., Pediaditakis, I., Gravanis, A., Simi, A., \& Ibáñez, C. F. (2012). Genetic dissection of neurotrophin signaling through the p75 neurotrophin receptor. Cell Rep, 2, 1563-1570.

Choi, D. C., Maguschak, K. A., Ye, K., Jang, S. W., Myers, K. M., \& Ressler, K. J. (2010). Prelimbic cortical BDNF is required for memory of learned fear but not extinction or innate fear. Proc Natl Acad Sci USA, 107, 2675-2680. 
Cohen, S., Levi-Montalcini, R., \& Hamburger, V. (1954). A nerve growth-stimulating factor isolated from sarcomas 37 and 180. Proc Natl Acad Sci USA, 40, 1014-1018.

Cohen-Cory, S., \& Fraser, S. E. (1994). BDNF in the development of the visual system of Xenopus. Neuron, 12, 747-761.

D’Aniello, S., Irimia, M., Maeso, I., Jiménez-Delgado, S., Pascual-Anaya, J., ... GarciaFernàndez, J. (2008). Gene expansion and retention leads to a diverse Tyrosine kinase superfamily in amphioxus. Mol Biol Evol, 25, 1841-1854.

Daub, H., Weiss, F. U., Wallasch, C., \& Ullrich, A. (1996). Role of transactivation of the EGF receptor in signaling by G-protein coupled receptors. Nature, 379, 557-560.

Dawbarn, D., \& Allen, S. J. (2003). Neurotrophins and neurodegeneration. Neuropathol Appl Neurobiol, 29, 211-230.

De Felice, E., Porreca, I., Alleva, E., De Girolamo, P., Ambrosino, C., ... Sordino, P. (2014) Localization of BDNF expression in the developing brain of zebrafish. $J$ Anat, 224, 564-574.

Dehal, P., \& Boore, J. L. (2005). Two rounds of whole genome duplication in the ancestral vertebrate. PLoS Biol, 3(10), e314.

Dyer, C., Linker, C., Graham, A., \& Knight, R. (2014). Specification of sensory neurons occurs through diverse developmental programs functioning in the brain and spinal cord. Dev Dyn, 243, 1429-1439.

Donovan, M. J., Hahn, R., Tessarollo, L., \& Hempstead, B. L. (1996). Identification of an essential nonneuronal function of neurotrophin 3 in mammalian cardiac development. Nat Genet, 14, 210-213. 
Donovan, M. J., Lin, M. I., Wiegn, P., Ringstedt, T., Kraemer, R., ... Hempstead, B., L. (2000). Brain derived neurotrophic factor is an endothelial cell survival factor required for intramyocardial vessel stabilization. Development, 127, 4531-4540.

Durand, C., Robin, C., Bollerot, K., Baron, M. H., Ottersbach, K., \& Dzierzak, E. (2007). Embryonic stromal clones reveal developmental regulators of definitive hematopoietic stem cells. Proc Natl Acad Sci USA, 104, 20838-20843.

Eaton, M. J., \& Whittemore, S. R. (1996). Autocrine BDNF secretion enhances the survival and serotonergic differentiation of raphe neuronal precursor cells grafted into the adult rat CNS. Exp Neurol, 140, 105-114.

English, A. W., Cucoranu, D., Mulligan, A., Rodriguez, J., A., \& Sabatier, M. J. (2011). Neurotrophin-4/5 is implicated in the enhancement of axon regeneration produced by treadmill training following peripheral nerve injury. Eur J Neurosci, 33, 2265-2271.

Feng, N., Huke, S., Zhu, G., Tocchetti, C. G., Shi, S., ... Paolocci, N. (2015). Constitutive BDNF/TrkB signaling is required for normal cardiac contraction and relaxation. Proc Natl Acad Sci USA, 112, 1880-1885.

Fox, E. A., Phillips, R. J., Baronowsky, E. A., Byerly, M. S., Jones, S., \& Powley, T. L. (2001). Neurotrophin-4 deficient mice have a loss of vagal intraganglionic mechanoreceptors from the small intestine and a disruption of short-term satiety. $J$ Neurosci, 21, 8602-8615.

Frade, J. M., \& López-Sánchez, N. (2010). A novel hypothesis for Alzheimer disease based on neuronal tetraploidy induced by p75 (NTR). Cell Cycle, 9, 1934-1941.

Garcia, T. B., Hollborn, M., \& Bringmann, A. (2017). Expression and signaling of NGF in the healthy and injured retina. Cytokine Growth Factor Rev, 34, 43-57. 
Gasanov, E. V., Rafieva, L. M., \& Korzh, V. P. (2015). BDNF-TrkB axis regulates migration of the lateral line primordium and modulates the maintenance of mechanoreceptor progenitors. PLoS One, 10, e0119711.

Germanà, A., Laurà, R., Montalbano, G., Guerrera, M. C., Amato, V., ... Vega, J. A. (2010). Expression of brain-derived neurotrophic factor and TrkB in the lateral line system of zebrafish during development. Cell Mol Neurobiol, 30, 787-793.

Gotz, R., Koster, R., Winkler, C., Raulf, F., Lottspeich, F., ... Thoenen, H. (1994). Neurotrophin-6 is a new member of the nerve growth factor family. Nature, 372, 266-269.

Hackam, A. S. (2008). Regulation of neurotrophin expression and activity in the retina. Adv Exp Med Biol, 613, 343-349.

Hallböök, F., Bäckström, A., Kullander, K., Ebendal, T., \& Carri, N. G. (1996). Expression of neurotrophins and trk receptors in the avian retina. J Comp Neurol, 364, 664-676.

Hallböök, F., Lundin, L. G., \& Kullander, K. (1998). Lampetra fluviatilis neurotrophin homolog, descendant of a neurotrophin ancestor, discloses the early molecular evolution of neurotrophins in the vertebrate subphylum. J Neurosci, 18, 8700-8711.

Hallböök, F., Wilson, K., Thorndyke, M., \& Olinski, R. P. (2006). Formation and evolution of the chordate neurotrophin and Trk receptor genes. Brain Behav Evol, 68,133-144.

Han, H. W., Chou, C. M., Chu, C. Y., Cheng, C. H., Yang, C. H., ... Huang, C. J. (2014). The Nogo-C2/Nogo receptor complex regulates the morphogenesis of zebrafish lateral line primordium through modulating the expression of $\mathrm{dkk} 1 \mathrm{~b}$, a Wnt signal inhibitor. PLoS One, 9, e86345.

Hannestad, J., Marino, F., Germanà, A., Catania, S., Abbate, F., ... Vega, J. A. (2000). Trk neurotrophin receptor-like proteins in the teleost Dicentrarchus labrax. Cell Tissue Res, 300, 1-9. 


\section{$\longrightarrow$ \\ (1)}

Harrington, A. W., \& Ginty, D. D. (2013). Long-distance retrograde neurotrophic factor signalling in neurons. Nat Rev Neurosci, 14, 177-187.

Heinrich, G., \& Lum, T. (2000). Fish neurotrophins and Trk receptors. Int J Dev Neurosci, $18,1-27$.

Hohn, A., Leibrock, J., Bailey, K., \& Barde, Y. A. (1990). Identification and characterization of a novel member of the nerve growth factor/brain-derived neurotrophic factor family. Nature, 344, 339-341.

Houtz, J., Borden, P., Ceasrine, A., Minichiello, L., \& Kuruvilla, R. (2016) Neurotrophin signaling is required for glucose-induced insulin secretion. Dev Cell, 39, 329-345.

Ito, K., \& Enomoto, H. (2016). Retrograde transport of neurotrophic factor signaling: implications in neuronal development and pathogenesis. J Biochem, 160, 77-85.

Kim, H. C., Cho, Y. J., Ahn, C. W., Park, K. S., Kim, J. C., ... Lee, H. K. (2009). Nerve growth factor and expression of its receptors in patients with diabetic neuropathy. Diabet Med, 26, 1228-1234.

Kim, E., Jeong, I., Kim, S., Kim, H. K., Lee, D. W., .. Park, H. C. (2016). Distribution of galanin receptor $2 \mathrm{~b}$ neurons and interaction with galanin in the zebrafish central nervous system. Neurosci Lett, 628, 153-160.

Kimmel, C. B., Ballard, W. W., Kimmel, S. R., Ullmann, B., \& Schilling, T. F. (1995). Stages of embryonic development of the zebrafish. Dev Dyn, 203, 253-310.

Knaut, H., Blader, P., Strähle, U., \& Schier, A. F. (2005). Assembly of trigeminal sensory ganglia by chemokine signaling. Neuron, 47, 653-666. 
Jaaro, H., Beck, G., Conticello, S. G., \& Fainzilber, M. (2001). Evolving better brains: a need for neurotrophins? Trends Neurosci, 24, 79-85.

Jaaro, H., \& Fainzilber, M. (2006). Building complex brains - missing pieces in an evolutionary puzzle. Brain Behav Evol, 68, 191-195.

Lagler K., L., Bardach, J. E., \& Miller R. R. (1967). Ichthyology: the study of fishes. John Wiley, New York.

Lanave, C., Colangelo, A., M., Saccone, C., \& Alberghina, L. (2007). Molecular evolution of the neurotrophin family members and their Trk receptors. Gene, 394,1-12.

Lapraz, F., Röttinger, E., Duboc, V., Range, R., Duloquin, L., ... Thierry, L. (2006). RTK and TGF-beta signaling pathways genes in the sea urchin genome. Dev Biol, 300, 132152.

Larrieta, M. E., Vital, P., Mendoza-Rodríguez, A., Cerbon, M., \& Hiriart, M. (2006). Nerve growth factor increases in pancreatic beta cells after streptozotocin-induced damage in rats. Exp Biol Med, 231, 396-402.

Laske, C., Stellos, K., Hoffmann, N., Stransky, E., Straten, G., ... Leyhe, T. (2011). Higher BDNF serum levels predict slower cognitive decline in Alzheimer's disease patients. Int $J$ Neuropsychopharmacol, 14, 399-404.

Lauri, A., Bertucci, P., \& Arendt, D. (2016). Neurotrophin, p75, and Trk signaling module in the developing nervous system of the marine annelid Platynereis dumerilii. Biomed Res Int, 2456062.

Lauterborn, J. C., Isackson, P. J., \& Gall, C. M. (1994). Cellular localization of NGF and NT-3 mRNAs in postnatal rat forebrain. Mol Cell Neurosci, 5, 46-62. 
Lee, F. S., \& Chao, M. V. (2001). Activation of Trk neurotrophin receptors in the absence of neurotrophins. Proc Natl Acad Sci USA, 98, 3555-3560.

Lin, M., Das, I., Schwartz, G., Tsoulfas, P., Mikawa, T., \& Hempstead, B. (2000). Trk C receptor signaling regulates cardiac myocyte proliferation during early heart development in vivo. Dev Biol, 226, 180-191.

Liu, X., Robinson, M. L., Schreiber, A. M., Wu, V., Lavail, M. M., ... Copenhagen, D. R. (2009). Regulation of neonatal development of retinal ganglion cell dendrites by neurotrophin-3 overexpression. J Comp Neurol, 514, 449-458.

Logan, A., Ahmed, $\quad$ Z., Baird, $\quad$ A., Gonzalez, $\quad$ A. $\quad$ M., \& Berry, $\quad$ M. (2006). Neurotrophic factor synergy is required for neuronal survival and disinhibited axon regeneration after CNS injury. Brain, 129, 490-502.

Lum, T., Huynh, G., \& Heinrich, G. (2001). Brain-derived neurotrophic factor and TrkB tyrosine kinase receptor gene expression in zebrafish embryo and larva. Int $J$ Dev Neurosci, 19, 569-587.

Martin, S. C., Marazzi, G., Sandell, J. H., \& Heinrich, G. (1995). Five Trk receptors in the zebrafish. Dev Biol, 169, 745-758.

Martin, S. C., Sandell, J. H., \& Heinrich, G. (1998). Zebrafish TrkC1 and TrkC2 receptors define two different cell populations in the nervous system during the period of axonogenesis. Dev Biol, 195, 114-130.

Meloni, M., Caporali, A., Graiani, G., Lagrasta, C., Katare, R., ... Emanueli, C. (2010). Nerve Growth Factor promotes cardiac repair following myocardial infarction. Circ Res, 106:1275-1284. 
Meyer, A., \& Schartl, M. (1999). Gene and genome duplications in vertebrates: the one-tofour (-to-eight in fish) rule and the evolution of novel gene functions. Curr Opin Cell Biol, $11,699-704$.

Minnone, G., De Benedetti, F., \& Bracci-Laudiero, L. (2017) NGF and its receptor in the regulation of inflammatory response. Int J Mol Sci 18, 1028.

Miralles, F., Philippe, P., Czernichow, P., \& Scharfmann, R. (1998). Expression of nerve growth factor and its high-affinity receptor TrkA in the rat pancreas during embryonic and fetal life. J Endocrinol, 156, 431-439

Morimura, R., Nozawa, K., Tanaka, H., \& Ohshima, T. (2013). Phosphorylation of Dpsyl2 (CRMP2) and Dpsyl3 (CRMP4) is required for positioning of caudal primary motor neurons in the zebrafish spinal cord. Dev Neurobiol, 73, 911-920.

Mueller, T. (2012). What is the thalamus in zebrafish? Front Neurosci, 6, 1-14.

Nagahara, A. H., \& Tuszynski, M. H. (2011). Potential therapeutic uses of BDNF in neurological and psychiatric disorders. Nat Rev Drug Discov, 10, 209-219.

Nakagawara, A. (2001). Trk receptor tyrosine kinases: a bridge between cancer and neural development. Cancer Lett, 169, 107-114.

Nilsson, A. S., Fainzilber, M., Falck, P., \& Ibanez, C. F. (1998). Neurotrophin-7: a novel member of the neurotrophin family from the zebrafish. FEBS Letters, 424, 285-290.

Oberg-Welsh, C., \& Welsh, M. (1996). Effects of certain growth factors on in vitro maturation of rat fetal islet-like structures. Pancreas, 12, 334-339.

Ohno, S. Patterns in genome evolution (1993). Curr Opin Genet Dev, 3, 911-914 
Ohta, T., Numata, M., Tsukioka, Y., Futagami, F., Kayahara, M., .. Nakanuma, Y. (1997). Neurotrophin-3 expression in human pancreatic cancers. J Pathol, 181, 405-412.

Palanca, A. M., Lee, S. L., Yee, L. E., Joe-Wong, C., Trinh, L. A., .. Sagasti, A. (2013). New transgenic reporters identify somatosensory neuron subtypes in larval zebrafish. Dev Neurobiol, 73, 152-167.

Pan, Y. A., Choy, M., Prober, D. A., \& Schier, A. F. (2012). Robo2 determines subtypespecific axonal projections of trigeminal sensory neurons. Development, 139, 591-600.

Proenca, C. C., Song, M., \& Lee, F. S. (2016). Differential effects of BDNF and neurotrophin 4 (NT4) on endocytic sorting of TrkB receptors. J Neurochem, 138, 397-406.

Rajagopal, R., Chen, Z. Y., Lee, F. S., \& Chao, M. V. (2004). Transactivation of Trk neurotrophin receptors by G-protein-coupled receptor ligands occurs on intracellular membranes. J Neurosci, 24, 6650-6658.

Reichardt, L. F. (2006). Neurotrophin-regulated signalling pathways. Phil Trans $R$ Soc B, $361,1545-1564$.

Robles, E., Smith, S. J., \& Baier, H. (2011). Characterization of genetically targeted neuron types in the zebrafish optic tectum. Front Neural Circuits, 5, 1.

Rowe, T. B., Macrini, T. E., \& Luo, Z. X. (2011). Fossil evidence on origin of the mammalian brain. Science, 332, 955-957.

Salvioli, B., Bovara, M., Barbara, G., De Ponti, F., Stanghellini, V., ... De Giorgio, R. (2002). Neurology and neuropathology of the pancreatic innervation. J Pancreas, 3, 26-33.

Santos, E., Romero-Alemán, M. M., Monzón-Mayor, M., Lang, D. M., Rodger, J., \& Yanes, C. (2011). Expression of BDNF and NT-3 during the ontogeny and regeneration of the lacertidian (Gallotia galloti) visual system. Dev Neurobiol, 71, 836-853. 


\section{$\square$}

Sievers, F., Wilm A., Dineen, D., Gibson, T. J., Karplus, K., ... Higgins, D. G. (2011). Fast, scalable generation of high-quality protein multiple sequence alignments using Clustal Omega. Mol Syst Biol, 7, 539.

Sossin, W. S. (2006). Tracing the evolution and function of the Trk superfamily of receptor tyrosine kinases. Brain Behav Evol, 68, 145-156.

Tanaka, H., Nojima, Y., Shoji, W., Sato, M., Nakayama, R., ... Okamoto, H. (2011). Islet1 selectively promotes peripheral axon outgrowth in Rohon-Beard primary sensory neurons. Dev Dyn, 240, 9-22.

Taylor, J. S., Van de Peer, Y., Braasch, I., \& Meyer, A. (2001). Comparative genomics provides evidence for an ancient genome duplication event in fish. Philos Trans $R$ Soc Lond B Biol Sci, 356, 1661-1679.

Taylor, J. S., Braasch, I., Frickey, T., Meyer, A., \& Van de Peer, Y. (2003). Genome duplication, a trait shared by 22000 species of ray-finned fish. Genome Res, 13, 382-390.

Teitelman, G., Guz, Y., Ivkovic, S., \& Ehrlich, M. (1998). Islet injury induces neurotrophin expression in pancreatic cells and reactive gliosis of peri-islet Schwann cells. $J$ Neurobiol, 34, 304-318.

Tessarollo, L., Tsoulfas, P., Donovan, M. J., Palko, M. E., Blair-Flynn, J., ... Parada, L. F. (1997). Targeted deletion of all isoforms of the trkC gene suggests the use of alternate receptors by its ligand neurotrophin- 3 in neuronal development and implicates trkC in normal cardiogenesis. Proc Natl Acad Sci USA, 94,14776-14781.

Tettamanti, G., Cattaneo, A. G., Gornati, R., de Eguileor, M., Bernardini, G., \& Binelli, G. (2010). Phylogenesis of brain-derived neurotrophic factor (BDNF) in vertebrates. Gene, 450, 85-93. 
Thisse, B., \& Thisse, C. (2004). Fast Release Clones: A High Throughput Expression Analysis. ZFIN Direct Data Submission (http://zfin.org).

Thisse, C., \& Thisse, B. (2005). High Throughput Expression Analysis of ZF-Models Consortium Clones. ZFIN Direct Data Submission (http://zfin.org).

Thisse, B., Wright, G. J., \& Thisse, C. (2008). Embryonic and larval expression patterns from a large scale screening for novel low affinity extracellular protein interactions. ZFIN Direct Data Submission (http://zfin.org).

Venkatesh, B., Lee, A. P., Ravi, V., Maurya, A. K., Lian, M. M., ... Warren, W. C. (2014). Elephant shark genome provides unique insights into gnathostome evolution. Nature, 505, 174-179.

Vilar, M., \& Mira, H. (2016). Regulation of neurogenesis by neurotrophins during adulthood: expected and unexpected roles. Front Neurosci, 10, 26.

Warga, R. M., \& Kimmel, C. B. (1990). Cell movements during epiboly and gastrulation in zebrafish. Development, 108, 569-580.

Westerfield, M. (2000). The Zebrafish Book. A guide for the laboratory use of zebrafish (Danio rerio). University of Oregon Press, Eugene.

Williams, J. A., Barrios, A., Gatchalian, C., Rubin, L., Wilson, S. W., \& Holder, N. (2000). Programmed cell death in zebrafish rohon beard neurons is influenced by TrkC1/NT-3 signaling. Dev Biol, 226, 220-230.

Wilson, K. H. S. (2009). The genome sequence of the protostome Daphnia pulex encodes respective orthologues of a neurotrophin, a Trk and a p75NTR: Evolution of neurotrophin signaling components and related proteins in the bilateria. BMC Evol Biol, 9, 243. 


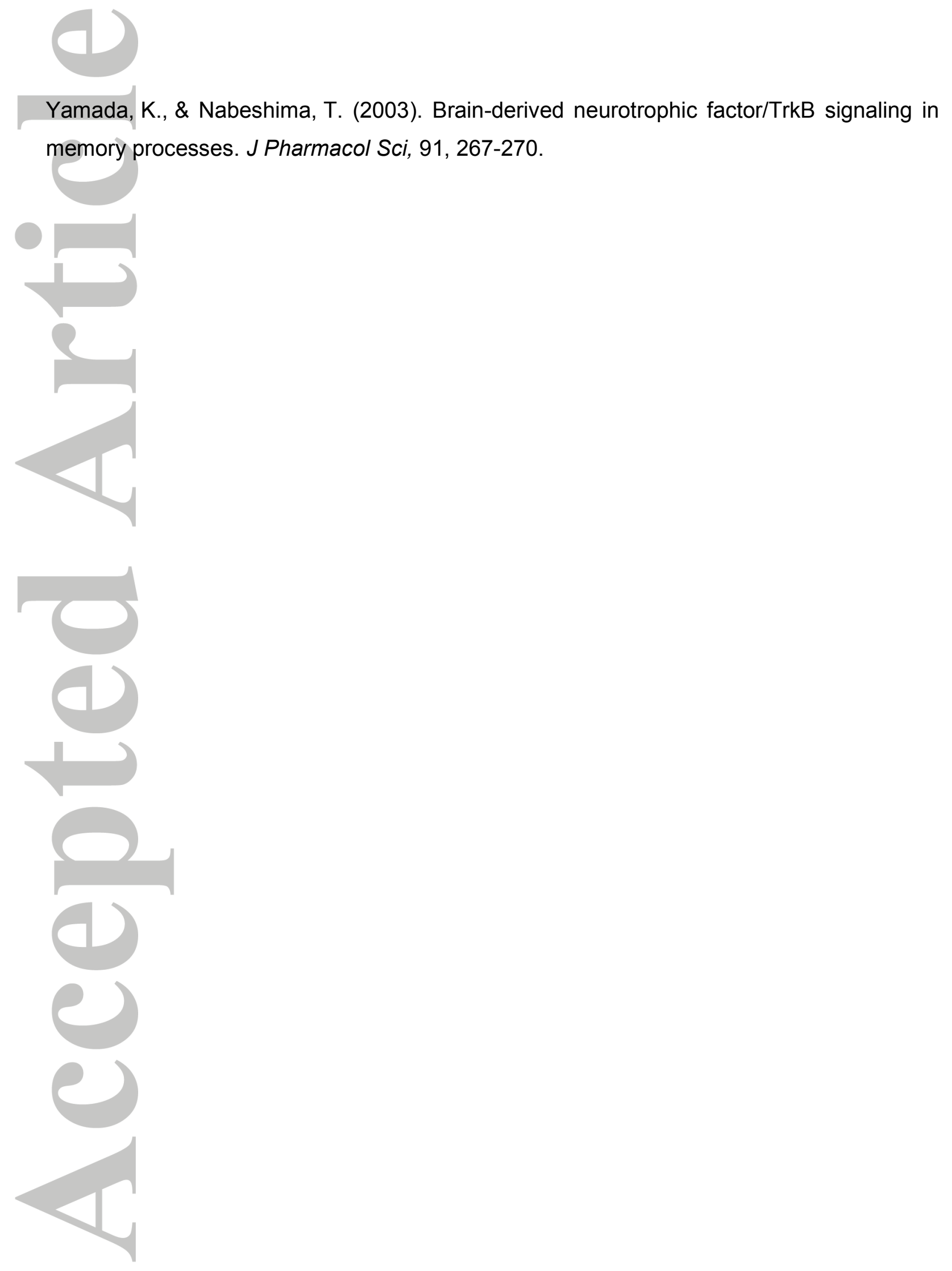




\section{FIGURE LEGENDS}

Figure 1. Three Ntrk receptor classes in vertebrates. Phylogenetic reconstruction using predicted proteins of gnathostome Ntrk receptor family. MrBayes tree shows the presence of three distinct Trk classes in all vertebrates analysed (except cyclostomes): Ntrk1 in red, Ntrk2 in blue, Ntrk3 in purple, and single-copy Ntrk of Branchiostoma floridae used as outgroup in yellow. Numbers on nodes represent posterior probabilities for Bayesian Inference. The scale bar represents expected changes per site.

Figure 2. ngf mRNA localizes to optic tectum. Whole-mount RNA in situ hybridization of ngf from 24 to $48 \mathrm{hpf}$. Embryos are oriented with head toward the left in lateral views (a$c, e)$, and head toward the left in ventral views (d,f). (a-b) Cells expressing $n g f$ in the optic tectum (ot), pharyngeal arches (ph), otic vesicle (ov), lateral line primordium (II) and posterior somites (ps) at $24 \mathrm{hpf}$ (c,d) At $36 \mathrm{hpf}$, ngf transcript in pharyngeal arches, trigeminal ganglion (tg) and posterior pharynx (pp). (e,f) Expression at $48 \mathrm{hpf}$ stays in lower jaw structures as paired cell clusters (arrowheads in $f$ ) and in the posterior pharynx. Scale bars: $100 \mu \mathrm{m}(\mathrm{a}, \mathrm{b}-\mathrm{f})$ and $150 \mu \mathrm{m}$ (a',a”).

Figure 3. Expression of $n t f 3$ in pituitary gland, retina, heart and pancreas. Wholemount RNA in situ hybridization of ntf3 from 12 to $72 \mathrm{hpf}$. Embryos and dissected eyes are oriented with head toward the left in dorsal views $(a, c)$, head toward the left in lateral views $(b, d, f, k)$, head toward the left in ventral views (e), and head toward the top in dorsal views $(\mathrm{g}, \mathrm{h})$. Cross (i) and longitudinal (k) sections are shown to identify the ntf3-expressing cell layers of the retina. $n t f 3$ activation in the epidermis surrounding the anterior margin of the neural plate (black arrowheads in a), otic vesicle (ov) and lateral line primordium (12 hpf). $(b, c)$ At 22 hpf, ntf3 expression is switched on in heart (he), pancreas (pa) and posterior somites (ps). (d,e,g) ntf3 mRNA in the central retina (cr) and pituitary gland (pg) at $48 \mathrm{hpf}$. (e') A lateral view of the pancreas at $48 \mathrm{hpf}$. (f) Small groups of neurons expressing $n t f 3$ in the brain (white arrowheads in $\mathrm{f}$; eyes have been removed to make brain signals visible). $(\mathrm{g}, \mathrm{h})$ Expression in the retina expands from central to peripheral retina $(\mathrm{g}, \mathrm{h})$. Whole-mount staining in photoreceptors (pr) out of the plane of focus is indicated by asterisks $(\mathrm{g}, \mathrm{h}) .(\mathrm{i}, \mathrm{j})$ 
Magnification of a cross section shows expression in the nuclear region (nr) and the outer segment (os) of the photoreceptor cell layer. (k) A second domain of $n t f 3$ expression spreads to the inner nuclear layer (inl) in the temporal retina (dashed line in $\mathrm{h}$; bracket in k). Abbreviations: gcl, ganglion cell layer; le, lens; di, diencephalon; rh, rhomboencephalon; tm, tegmentum. Scale bars: $100 \mu \mathrm{m}$ (a-f), $50 \mu \mathrm{m}$ (g-i) and $25 \mu \mathrm{m}$ (j).

Figure 4. Expression of $n t f 4 / 5$ and $n t f 6 / 7$ is highly specific. Whole-mount RNA in situ hybridization of $n t f 4 / 5$ from 12 to $96 \mathrm{hpf}(\mathrm{a}-\mathrm{j})$, and of $n t f 6 / 7$ from 16 to $48 \mathrm{hpf}$ (k-o). Embryos are oriented with head toward the left in lateral views (a,d-f,k,m-o), head toward the bottom in dorsal view (b), head toward the left in ventral views $(g, h)$, and in frontal views (c,l). (a-c) ntf4/5 transcript in the posterior epiblast (ep) at $12 \mathrm{hpf}$. (d,e) At $24 \mathrm{hpf}$, clusters of cranial nerves (arrowheads in d), lateral line primordium (II) and posterior median finfold (mf) express $n t f 4 / 5$. (f,g) Hybridization signal along pharyngeal arches (ph) at $48 \mathrm{hpf}(\mathrm{h}-\mathrm{j})$, persisting at its anterior margin (72 hpf). A new signal in the intestinal bulb (ib) at $96 \mathrm{hpf}$. (k-o) ntf6/7 expression in the otic vesicle (ov) from 16 to $48 \mathrm{hpf}$. Abbreviations: hp, hypoblast. Scale bars: $100 \mu \mathrm{m}(\mathrm{a}-\mathrm{n})$ and $50 \mu \mathrm{m}$ (o).

Figure 5. Neural and sensory cell types expressing ntrk1. Whole-mount RNA in situ hybridization of $n t r k 1$ from 24 to 72 hpf. Embryos are oriented with head toward the left in lateral views $(a, c, f)$ and head toward the left in dorsal views (b,d,e). (a,b) ntrk1 mRNA in cranial neurons (arrow), pectoral motor nerve ganglia (arrowhead) and Rohon-Beard (rb) neurons at 24 hpf. (d-f) Expression in trigeminal (white arrowhead), cranial (arrow) and pectoral (black arrowhead) neurons at 48 and 72 hpf. Abbreviations: ov, otic vesicle. Scale bars: $100 \mu \mathrm{m}$.

Figure 6. Overlapping and unique expression of $n$ trk2a and $n t r k 2 b$. Whole-mount RNA in situ hybridization of $n t r k 2 a(\mathrm{a}-\mathrm{g})$, and $n t r k 2 b(\mathrm{~h}-\mathrm{m})$ from 12 to $96 \mathrm{hpf}$. Embryos are oriented with head toward the left in lateral views $(a, b, d, e, g-i, k, m)$ and head toward the left in dorsal views $(\mathrm{c}, \mathrm{f}, \mathrm{j}, \mathrm{l})$. (a) Early ntrk2a transcript is localized in the hypoblast along the embryo at $12 \mathrm{hpf}$. (b-d) At $24 \mathrm{hpf}$, mRNA labeling in neurons of telencephalon (te), thalamus (th), hypothalamus (hy), tegmentum (tm), hindbrain (hb), cranial nerves (arrowheads in c), Rohon-Beard neurons (rb) and ventral cells in the neural tube that may 
represent motoneurons or interneurons (arrows). (e,f) At $48 \mathrm{hpf}$, ntrk2a is expressed in most brain regions. New domains present in the retinal ganglion cell layer and trigeminal ganglion (tg). (g) Diffuse expression at $96 \mathrm{hpf}$, with strong staining in the pharyngeal epithelium (pe). (h) Early ntrk2b transcript along the rostral end of the embryo at early somitogenesis (12 hpf). (l,j) Expression in telencephalon, ventral thalamus, tegmentum and hindbrain. $(k, l)$ Expression in the brain at $48 \mathrm{hpf}$, and in the retinal ganglion cell layer (gcl). (l) Signal across the brain at 96 hpf. Abbreviations: di, diencephalon; mb, midbrain. Scale bars: $100 \mu \mathrm{m}$.

Figure 7. Overlapping and unique expression of $n$ trk $3 a$ and $n t r k 3 b$. Whole-mount RNA in situ hybridization of $n t r k 3 a(a-g)$ from 24 to 72 hpf, and ntrk3b (h-m) from 24 to 96 hpf. Embryos are oriented with head toward the left in lateral views $(a, b, d, f, g, j, l)$, head toward the left in dorsal views (c,e,i,k). (a-c) At 24 hpf, ntrk3a expression is confined to nervous and sensory regions, including telencephalon (te), pineal gland (pn), posterior hypothalamus (hy) (white arrow in a), ventrorostral thalamus (th), cranial nerve ganglia (white arrowheads in a and c), posterior hindbrain (hb) (black arrow in a and c), otic vesicle (ov) and Rohon-Beard neurons (rb). mRNA across the brain and in pectoral motor nerve ganglia (arrowhead in e) from 48 to 72 hpf. (g-i) Expression of $n t r k 3 b$ in sub-groups of neuronal cell types in telencephalon, ventral thalamus, ventral tegmentum (tm) and otic vesicle (24 hpf). (j-I) Signal along the brain from 48 to $72 \mathrm{hpf}$, with weak expression in the ganglion cell layer ( $\mathrm{gcl})$. Background due to riboprobe trapping in the digestive system (asterisk in I). Scale bars: $100 \mu \mathrm{m}(\mathrm{a}-\mathrm{h}, \mathrm{j}-\mathrm{I})$ and $50 \mu \mathrm{m}$ (i).

Figure 8. Co-localization of bdnf and ntrk2a mRNAs. Double whole-mount in situ hybridization at $24 \mathrm{hpf}$. Embryo is oriented with head to the left in lateral view. (a) bdnf and ntrk2a are co-expressed in cranial nerves (arrows) (a', magnifications) but not in RohonBeard neurons (rb). Abbreviations: ov, otic vesicle. Scale bars: $100 \mu \mathrm{m}$.

Figure 9. Scheme of $n t$ and ntrk gene expression patterns in 24 hpf embryos. 


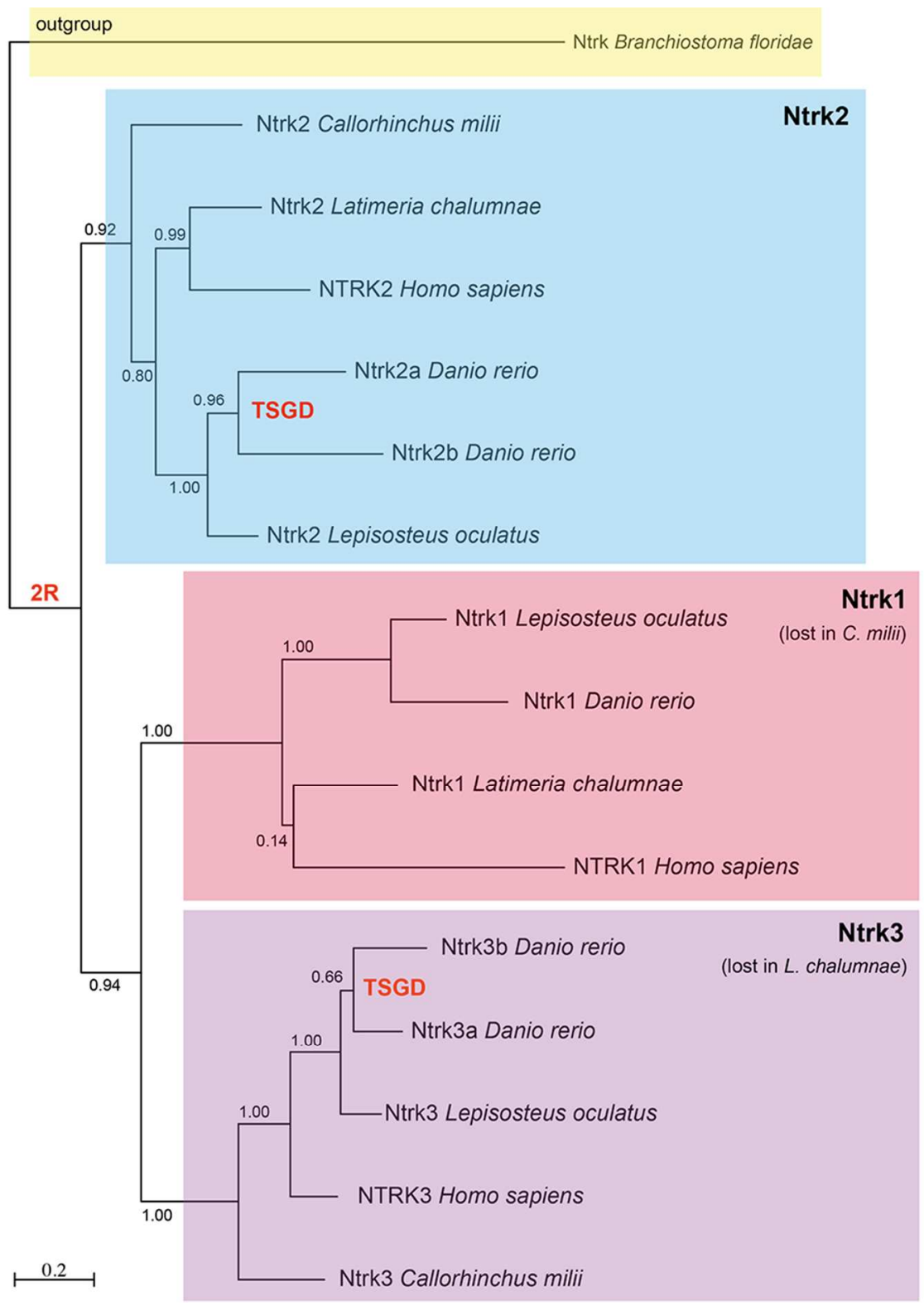

Figure 1. Three Ntrk receptor classes in vertebrates. Phylogenetic reconstruction using predicted proteins of gnathostome Ntrk receptor family. MrBayes tree shows the presence of three distinct Trk classes in all vertebrates analysed (except cyclostomes): Ntrk1 in red, Ntrk2 in blue, Ntrk3 in purple, and single-copy Ntrk of Branchiostoma floridae used as outgroup in yellow. Numbers on nodes represent posterior probabilities for Bayesian Inference. The scale bar represents expected changes per site.

$80 \times 109 \mathrm{~mm}(300 \times 300 \mathrm{DPI})$ 


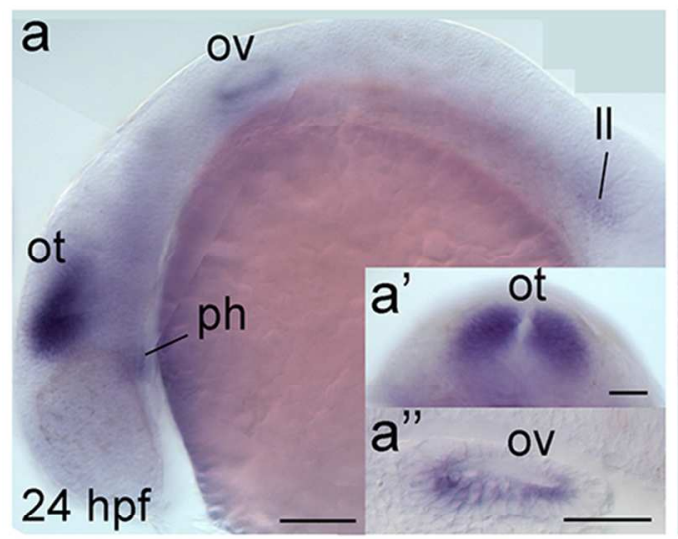

b
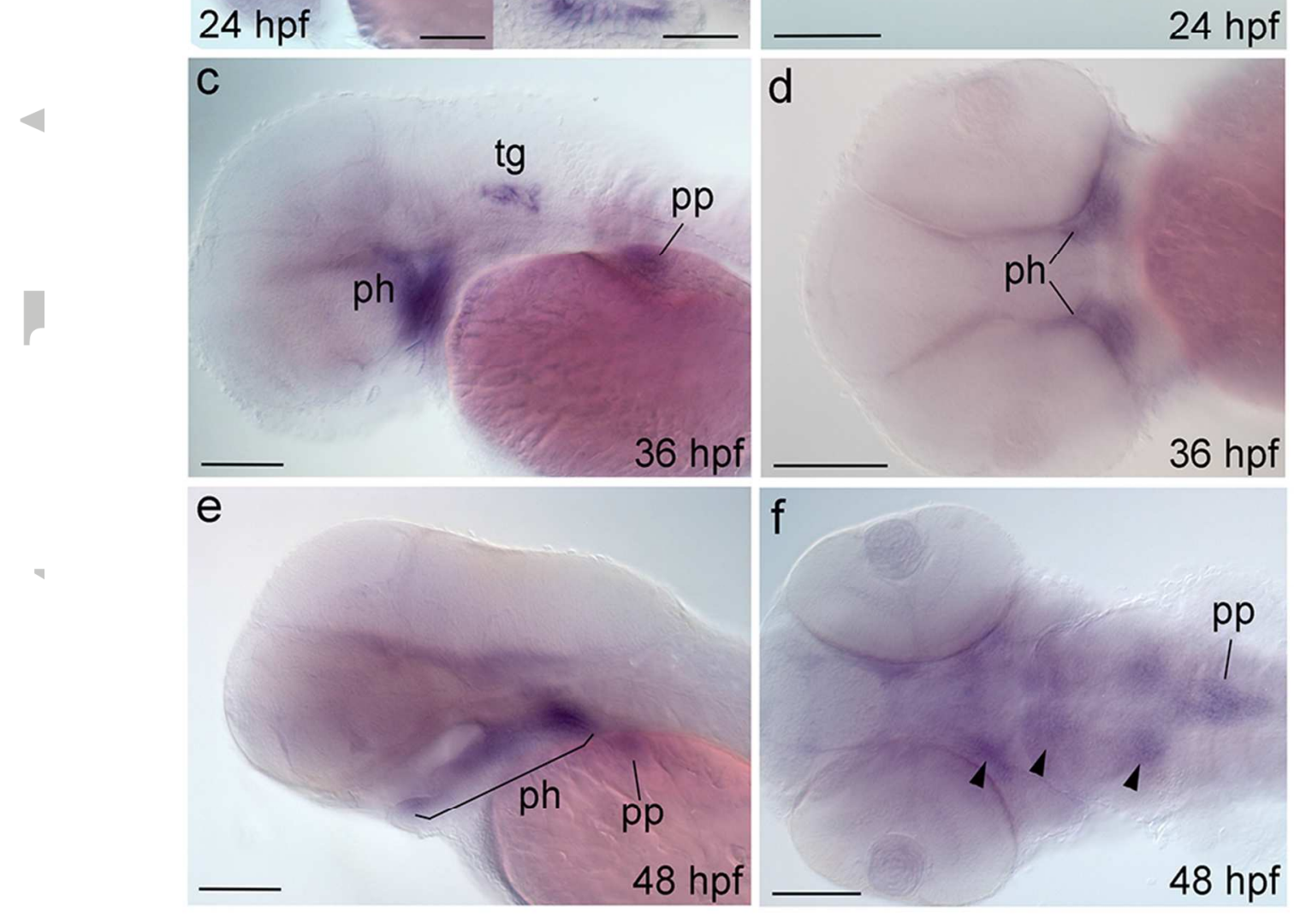

d
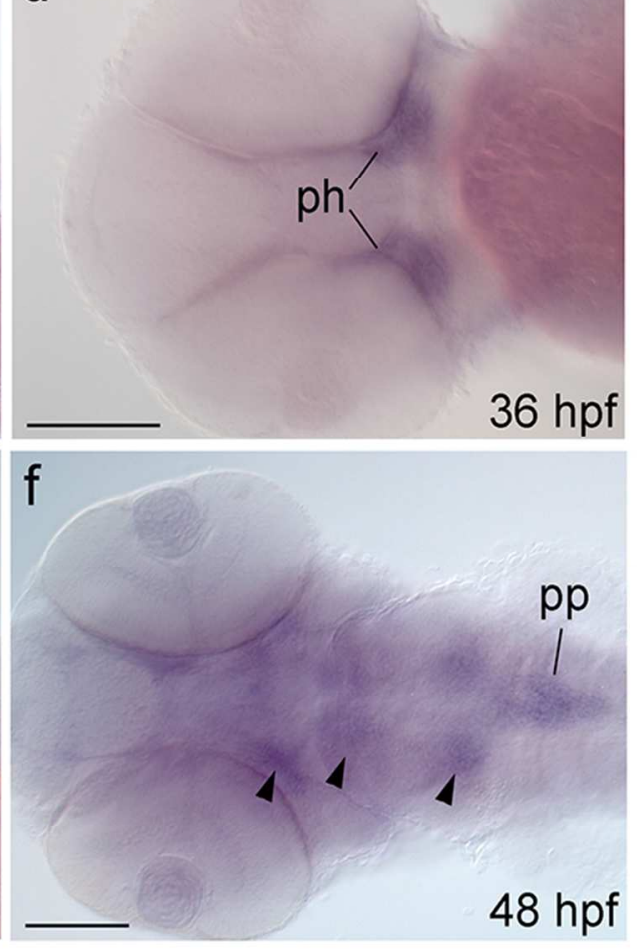

Figure 2. ngf mRNA localizes to optic tectum. Whole-mount RNA in situ hybridization of ngf from 24 to 48 hpf. Embryos are oriented with head toward the left in lateral views (a-c,e), and head toward the left in ventral views (d,f). (a-b) Cells expressing ngf in the optic tectum (ot), pharyngeal arches (ph), otic vesicle

(ov), lateral line primordium (II) and posterior somites (ps) at $24 \mathrm{hpf}$. (c, d) At $36 \mathrm{hpf}$, ngf transcript in pharyngeal arches, trigeminal ganglion (tg) and posterior pharynx (pp). $(e, f)$ Expression at $48 \mathrm{hpf}$ stays in lower jaw structures as paired cell clusters (arrowheads in $\mathrm{f}$ ) and in the posterior pharynx. Scale bars: 100 $\mu \mathrm{m}(\mathrm{a}, \mathrm{b}-\mathrm{f})$ and $150 \mu \mathrm{m}\left(\mathrm{a}^{\prime}, \mathrm{a}^{\prime \prime}\right)$.

$80 \times 95 \mathrm{~mm}(300 \times 300 \mathrm{DPI})$ 


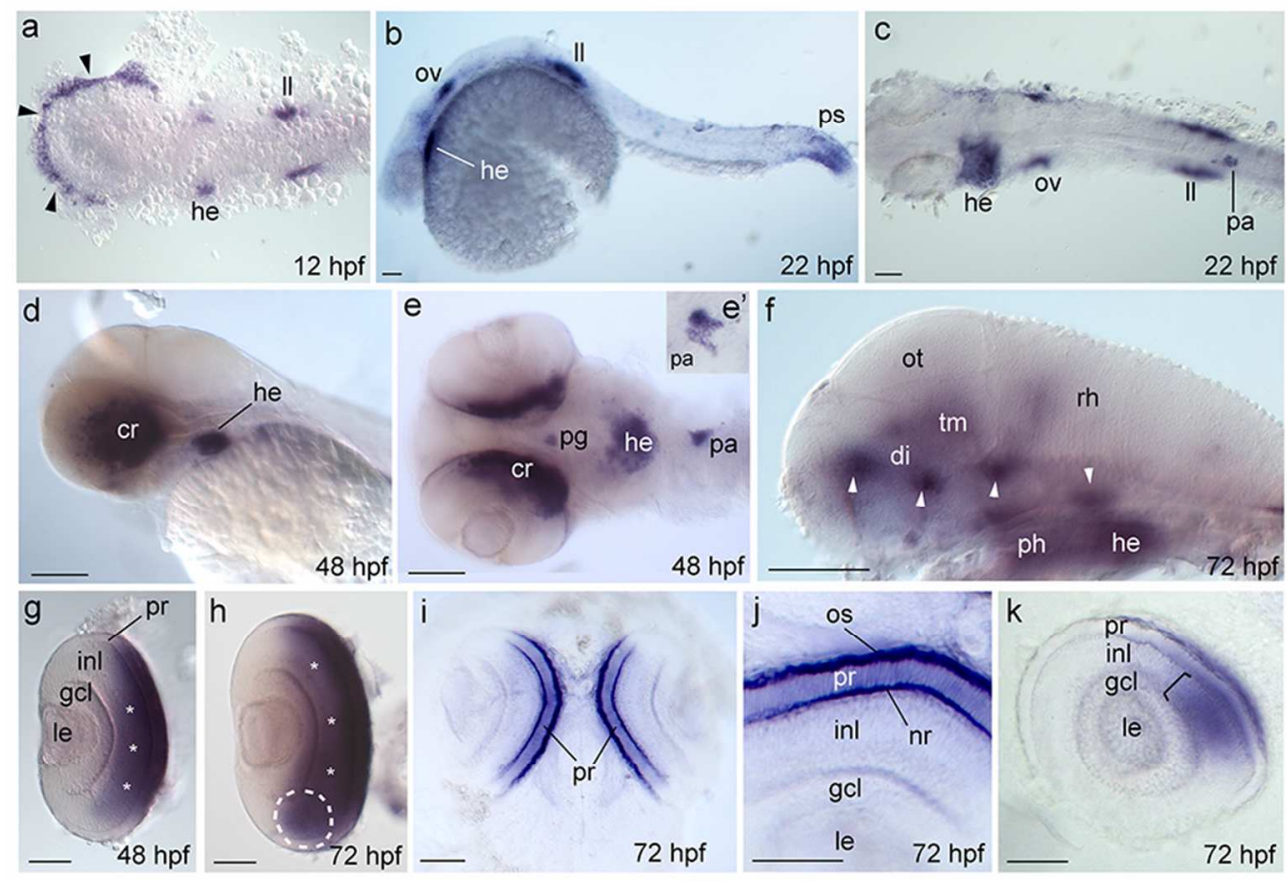

Figure 3. Expression of ntf3 in pituitary gland, retina, heart and pancreas. Whole-mount RNA in situ hybridization of ntf3 from 12 to $72 \mathrm{hpf}$. Embryos and dissected eyes are oriented with head toward the left in dorsal views $(a, c)$, head toward the left in lateral views $(b, d, f, k)$, head toward the left in ventral views (e), and head toward the top in dorsal views $(\mathrm{g}, \mathrm{h})$. Cross (i) and longitudinal $(\mathrm{k})$ sections are shown to identify the ntf3-expressing cell layers of the retina. ntf3 activation in the epidermis surrounding the anterior margin of the neural plate (black arrowheads in a), otic vesicle (ov) and lateral line primordium (12 hpf). (b,c) At 22 hpf, ntf3 expression is switched on in heart (he), pancreas (pa) and posterior somites (ps). (d,e,g) ntf3 mRNA in the central retina ( $\mathrm{cr}$ ) and pituitary gland $(\mathrm{pg})$ at $48 \mathrm{hpf}$. (e') A lateral view of the pancreas at 48

hpf. (f) Small groups of neurons expressing ntf3 in the brain (white arrowheads in f; eyes have been removed to make brain signals visible). $(\mathrm{g}, \mathrm{h}$ ) Expression in the retina expands from central to peripheral retina $(\mathrm{g}, \mathrm{h})$. Whole-mount staining in photoreceptors $(\mathrm{pr})$ out of the plane of focus is indicated by asterisks $(g, h) .(i, j)$ Magnification of a cross section shows expression in the nuclear region (nr) and the outer segment (os) of the photoreceptor cell layer. (k) A second domain of ntf3 expression spreads to the inner nuclear layer (inl) in the temporal retina (dashed line in $\mathrm{h}$; bracket in k). Abbreviations: gcl, ganglion cell layer; le, lens; di, diencephalon; rh, rhomboencephalon; tm, tegmentum. Scale bars: $100 \mu \mathrm{m}$ (a-f), $50 \mu \mathrm{m}$ $(\mathrm{g}-\mathrm{i})$ and $25 \mu \mathrm{m}(\mathrm{j})$.

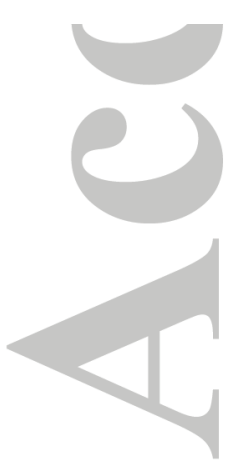

$80 \times 55 \mathrm{~mm}(300 \times 300$ DPI $)$ 

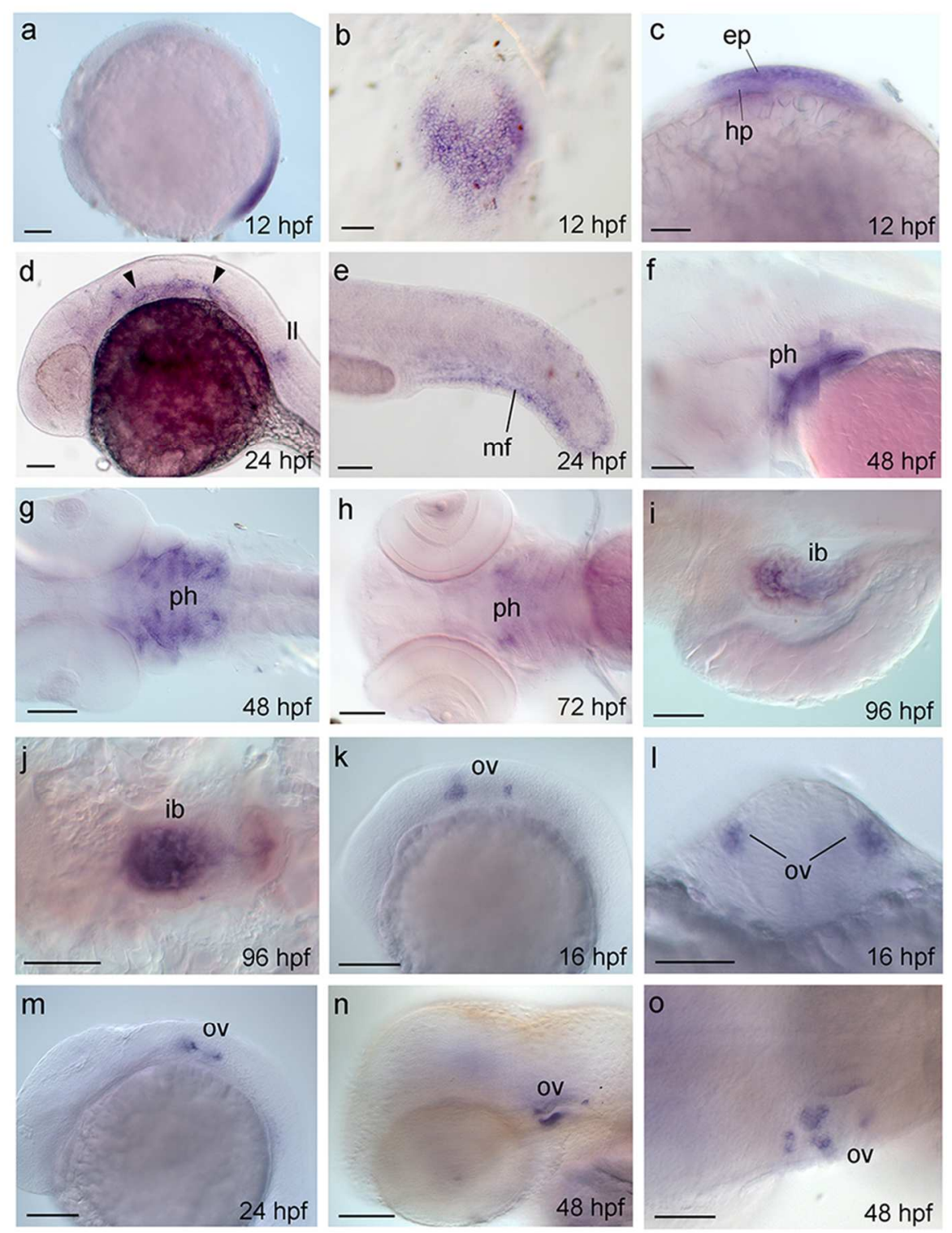

Figure 4. Expression of $n t f 4 / 5$ and $n t f 6 / 7$ is highly specific. Whole-mount RNA in situ hybridization of ntf4/5 from 12 to $96 \mathrm{hpf}(\mathrm{a}-\mathrm{j})$, and of ntf6/7 from 16 to $48 \mathrm{hpf}(\mathrm{k}-\mathrm{o})$. Embryos are oriented with head toward the left in lateral views $(a, d-f, k, m-0)$, head toward the bottom in dorsal view (b), head toward the left in ventral views $(\mathrm{g}, \mathrm{h})$, and in frontal views $(\mathrm{c}, \mathrm{l})$. (a-c) ntf4/5 transcript in the posterior epiblast (ep) at $12 \mathrm{hpf}$. (d,e) At $24 \mathrm{hpf}$, clusters of cranial nerves (arrowheads in d), lateral line primordium (II) and posterior median finfold (mf) express ntf4/5. (f,g) Hybridization signal along pharyngeal arches (ph) at $48 \mathrm{hpf}(\mathrm{h}-\mathrm{j})$, persisting at its anterior margin (72 hpf). A new signal in the intestinal bulb (ib) at $96 \mathrm{hpf}$. (k-0) ntf6/7 expression in the otic vesicle (ov) from 16 to 48 hpf. Abbreviations: hp, hypoblast. Scale bars: $100 \mu \mathrm{m}(\mathrm{a}-\mathrm{n})$ and $50 \mu \mathrm{m}(\mathrm{o})$.

$80 \times 104 \mathrm{~mm}(300 \times 300$ DPI $)$ 

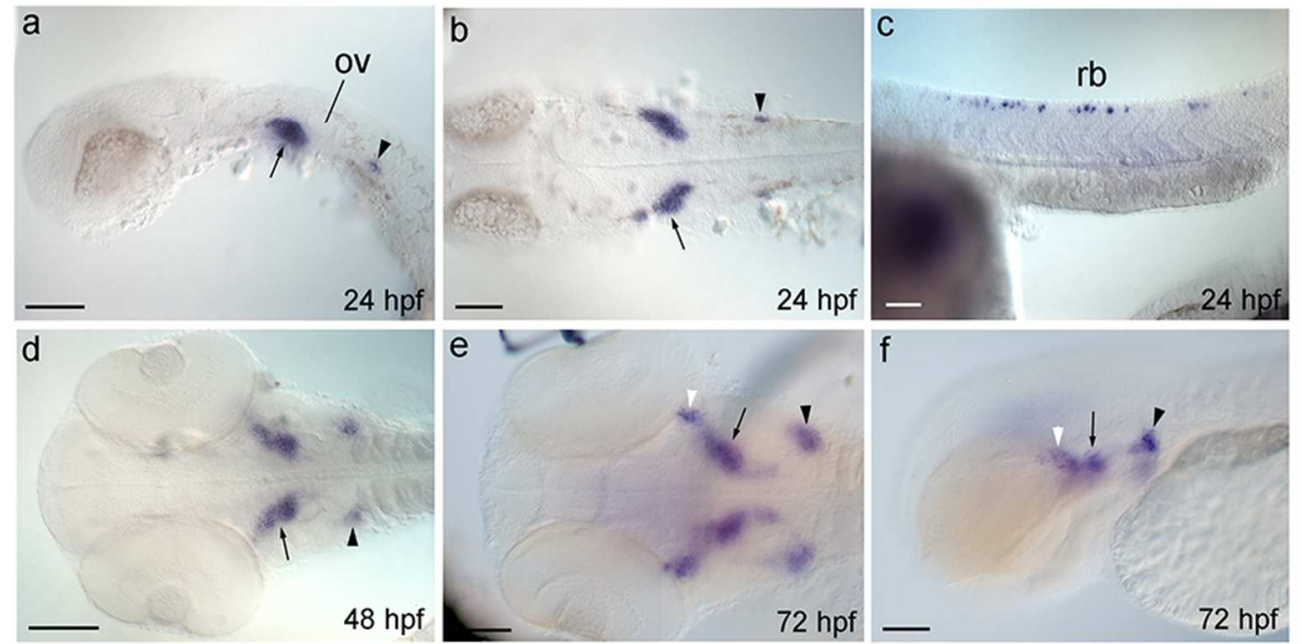

Figure 5. Few neural and sensory cell types expressing ntrk1. Whole-mount RNA in situ hybridization of ntrk1 from 24 to $72 \mathrm{hpf}$. Embryos are oriented with head toward the left in lateral views $(a, c, f)$ and head toward the left in dorsal views $(b, d, e) .(a, b)$ ntrk1 mRNA in cranial neurons (arrow), pectoral motor nerve ganglia (arrowhead) and Rohon-Beard ( $r b$ ) neurons at $24 \mathrm{hpf}$. (d-f) Expression in trigeminal (white arrowhead), cranial (arrow) and pectoral (black arrowhead) neurons at 48 and 72 hpf. Abbreviations: ov, otic vesicle. Scale bars: $100 \mu \mathrm{m}$.

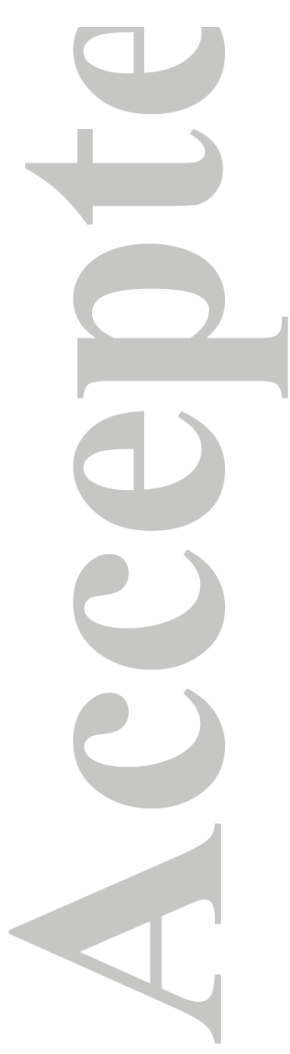

$80 \times 41 \mathrm{~mm}(300 \times 300 \mathrm{DPI})$ 

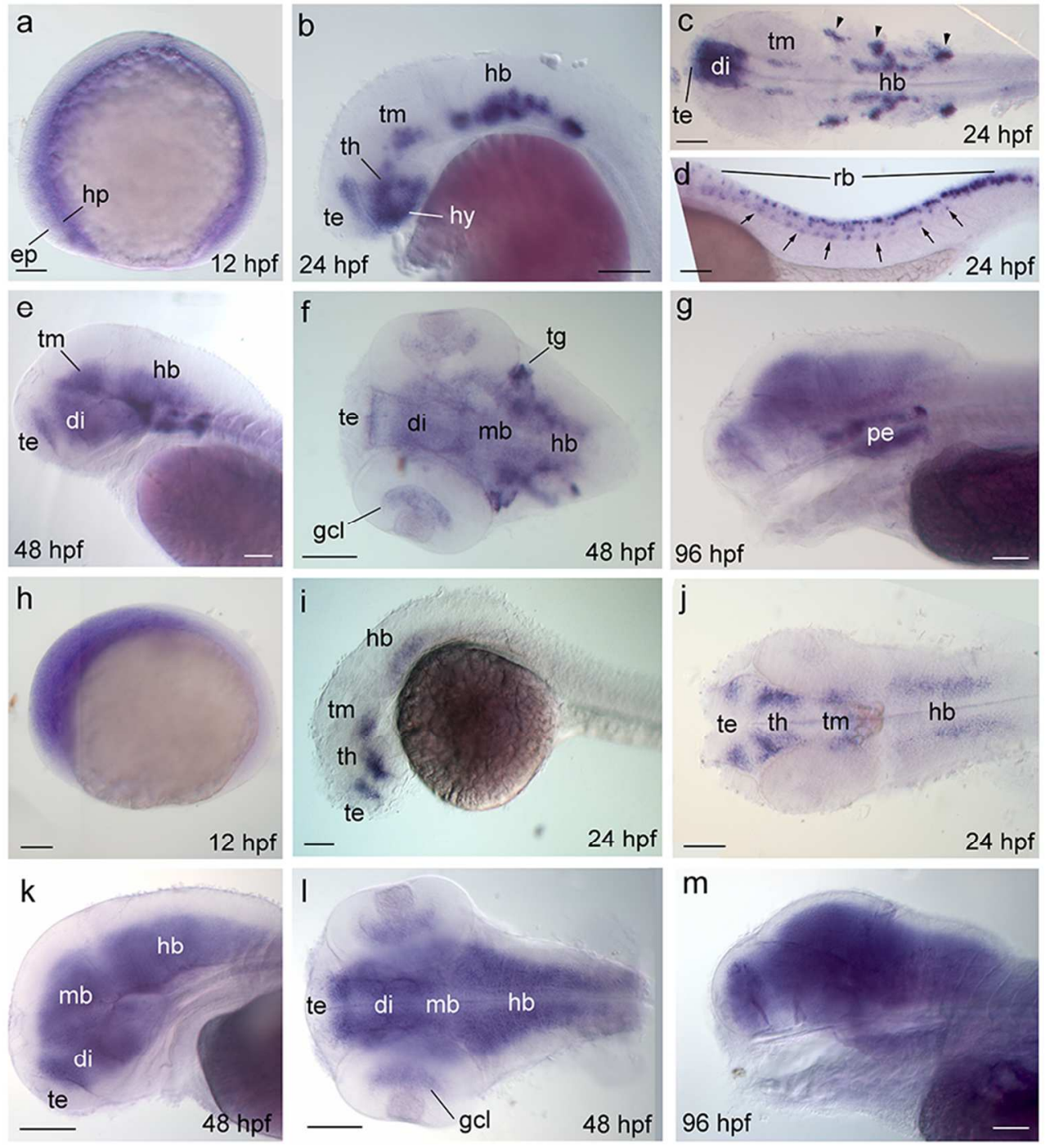

Figure 6. Overlapping and unique expression of ntrk2a and ntrk2b. Whole-mount RNA in situ hybridization of ntrk2a (a-g), and ntrk2b (h-m) from 12 to 96 hpf. Embryos are oriented with head toward the left in lateral views $(a, b, d, e, g-i, k, m)$ and head toward the left in dorsal views $(c, f, j, l)$. (a) Early ntrk2a transcript is localized in the hypoblast along the embryo at $12 \mathrm{hpf}$. (b-d) At $24 \mathrm{hpf}$, mRNA labeling in neurons of telencephalon (te), thalamus (th), hypothalamus (hy), tegmentum (tm), hindbrain (hb), cranial nerves (arrowheads in c), Rohon-Beard neurons ( $r b$ ) and ventral cells in the neural tube that may represent motoneurons or interneurons (arrows). (e,f) At $48 \mathrm{hpf}$, ntrk2a is expressed in most brain regions. New domains present in the retinal ganglion cell layer and trigeminal ganglion ( $\mathrm{tg}$ ). (g) Diffuse expression at 96 $\mathrm{hpf}$, with strong staining in the pharyngeal epithelium (pe). (h) Early ntrk2b transcript along the rostral end of the embryo at early somitogenesis $(12 \mathrm{hpf}) .(\mathrm{I}, \mathrm{j})$ Expression in telencephalon, ventral thalamus, tegmentum and hindbrain. $(\mathrm{k}, \mathrm{l})$ Expression in the brain at $48 \mathrm{hpf}$, and in the retinal ganglion cell layer (gcl). (I) Signal across the brain at 96 hpf. Abbreviations: di, diencephalon; mb, midbrain. Scale bars: $100 \mu \mathrm{m}$.

$$
80 \times 87 \mathrm{~mm}(300 \times 300 \mathrm{DPI})
$$



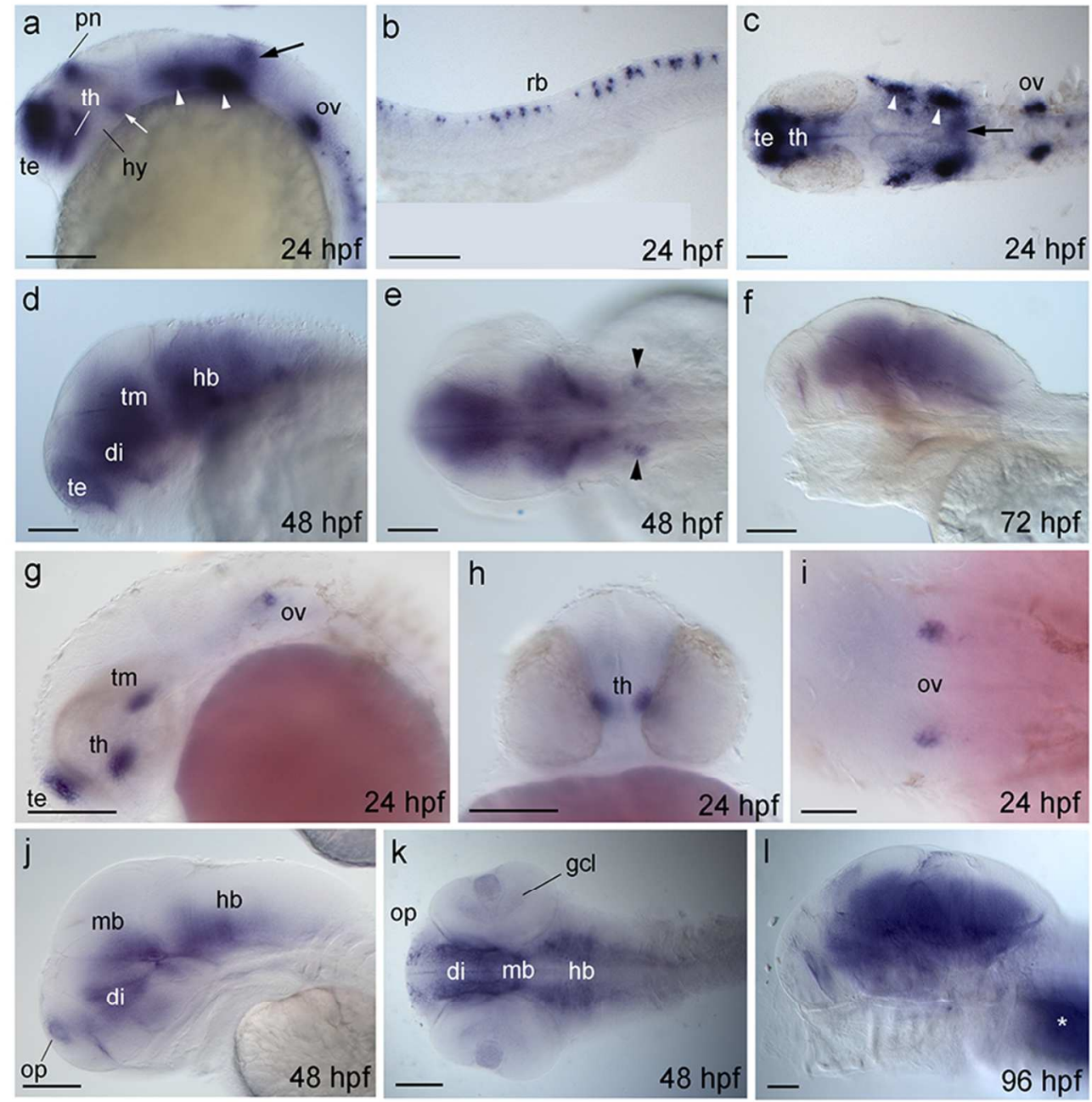

Figure 7. Overlapping and unique expression of ntrk3a and ntrk3b. Whole-mount RNA in situ hybridization of ntrk3a (a-g) from 24 to $72 \mathrm{hpf}$, and ntrk3b (h-m) from 24 to $96 \mathrm{hpf}$. Embryos are oriented with head toward the left in lateral views $(a, b, d, f, g, j, l)$, head toward the left in dorsal views $(c, e, i, k)$. (a-c) At 24 hpf, ntrk3a expression is confined to nervous and sensory regions, including telencephalon (te), pineal gland ( $\mathrm{pn}$ ), posterior hypothalamus (hy) (white arrow in a), ventrorostral thalamus (th), cranial nerve ganglia (white arrowheads in a and c), posterior hindbrain (hb) (black arrow in a and c), otic vesicle (ov) and Rohon-Beard neurons ( $r b$ ). mRNA across the brain and in pectoral motor nerve ganglia (arrowhead in e) from 48 to 72 hpf. ( $\mathrm{g}-\mathrm{i})$ Expression of ntrk3b in sub-groups of neuronal cell types in telencephalon, ventral thalamus, ventral tegmentum (tm) and otic vesicle (24 hpf). (j-l) Signal along the brain from 48 to $72 \mathrm{hpf}$, with weak expression in the ganglion cell layer $(\mathrm{gcl})$. Background due to riboprobe trapping in the digestive system (asterisk in I). Scale bars: $100 \mu \mathrm{m}(a-h, j-l)$ and $50 \mu \mathrm{m}(\mathrm{i})$.

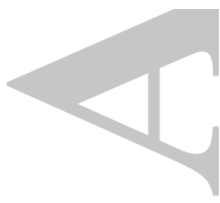

$80 \times 81 \mathrm{~mm}(300 \times 300 \mathrm{DPI})$ 


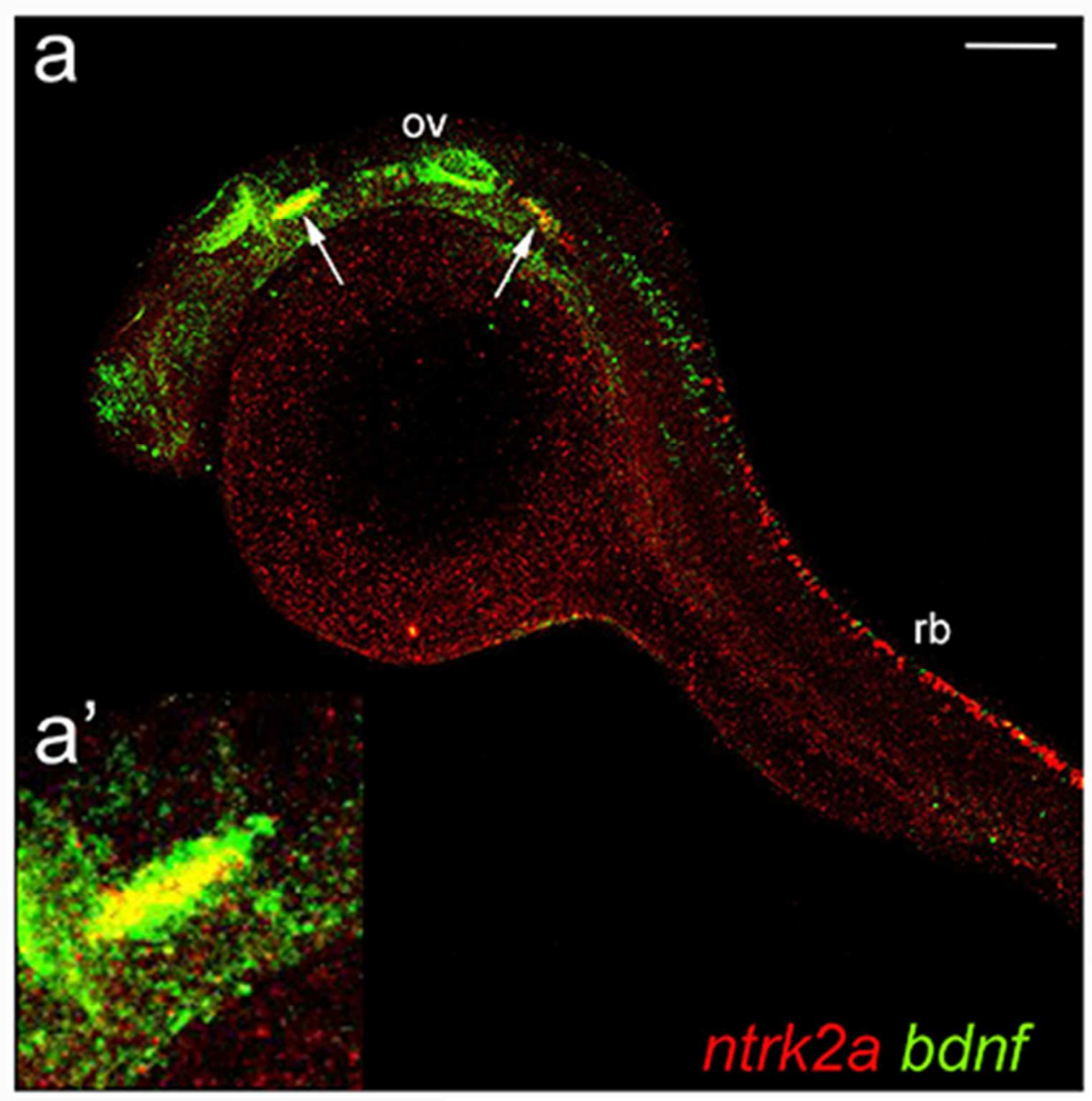

Figure 8. Co-localization of bdnf and ntrk2a mRNAs. Double whole-mount in situ hybridization at 24 hpf. Embryo is oriented with head to the left in lateral view. (a) bdnf and ntrk2a are co-expressed in cranial nerves (arrows) (a', magnifications) but not in Rohon-Beard neurons (rb). Abbreviations: ov, otic vesicle. Scale bars: $100 \mu \mathrm{m}$.

$79 \times 80 \mathrm{~mm}(300 \times 300$ DPI $)$ 

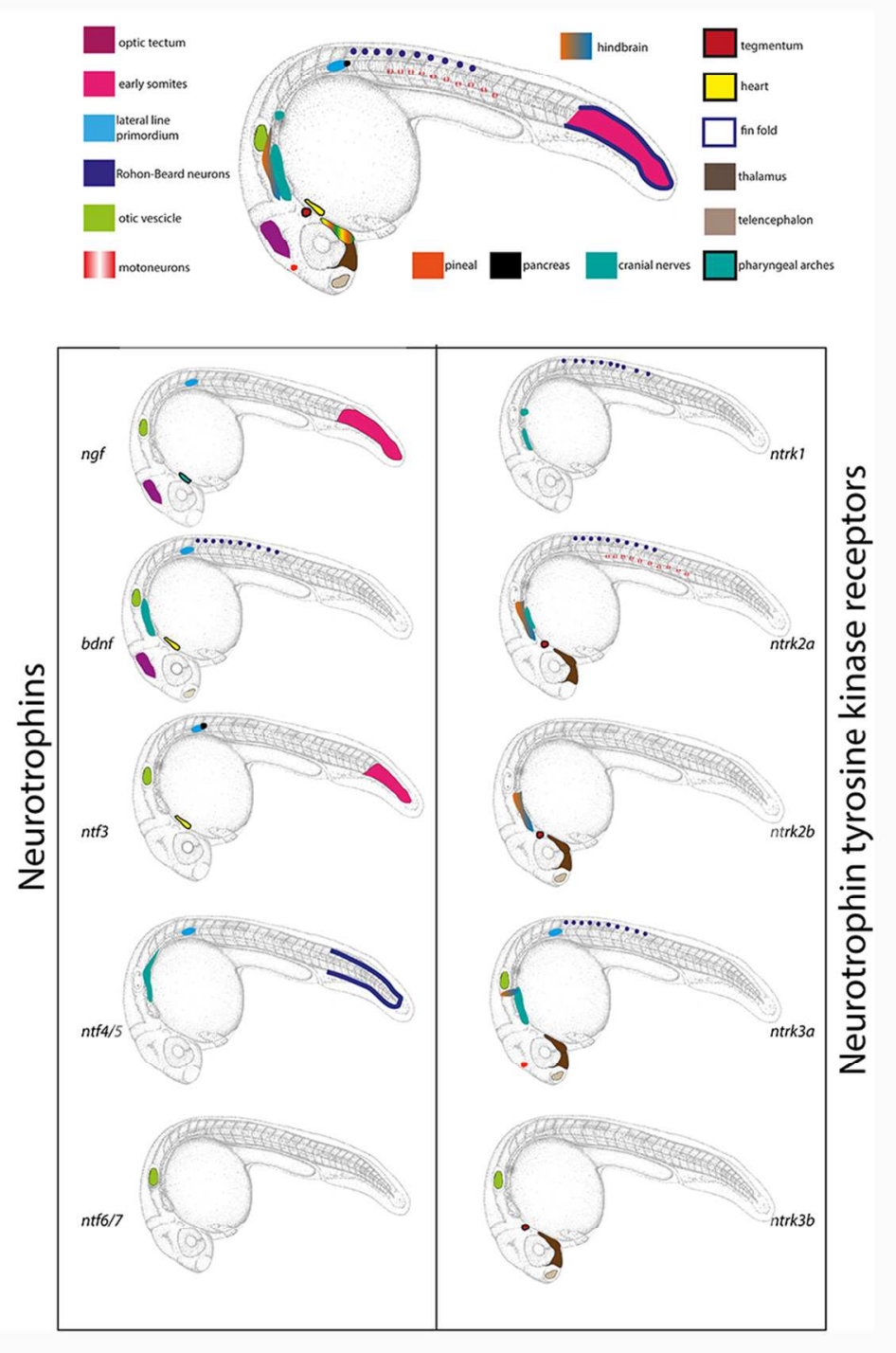

Figure 9. Scheme of nt and ntrk gene expression patterns in 24 hpf embryos.

$80 \times 120 \mathrm{~mm}(300 \times 300 \mathrm{DPI})$

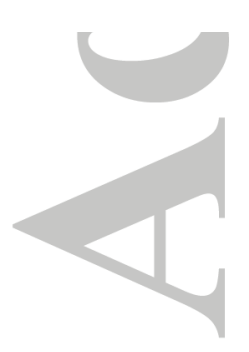

John Wiley \& Sons

This article is protected by copyright. All rights reserved. 


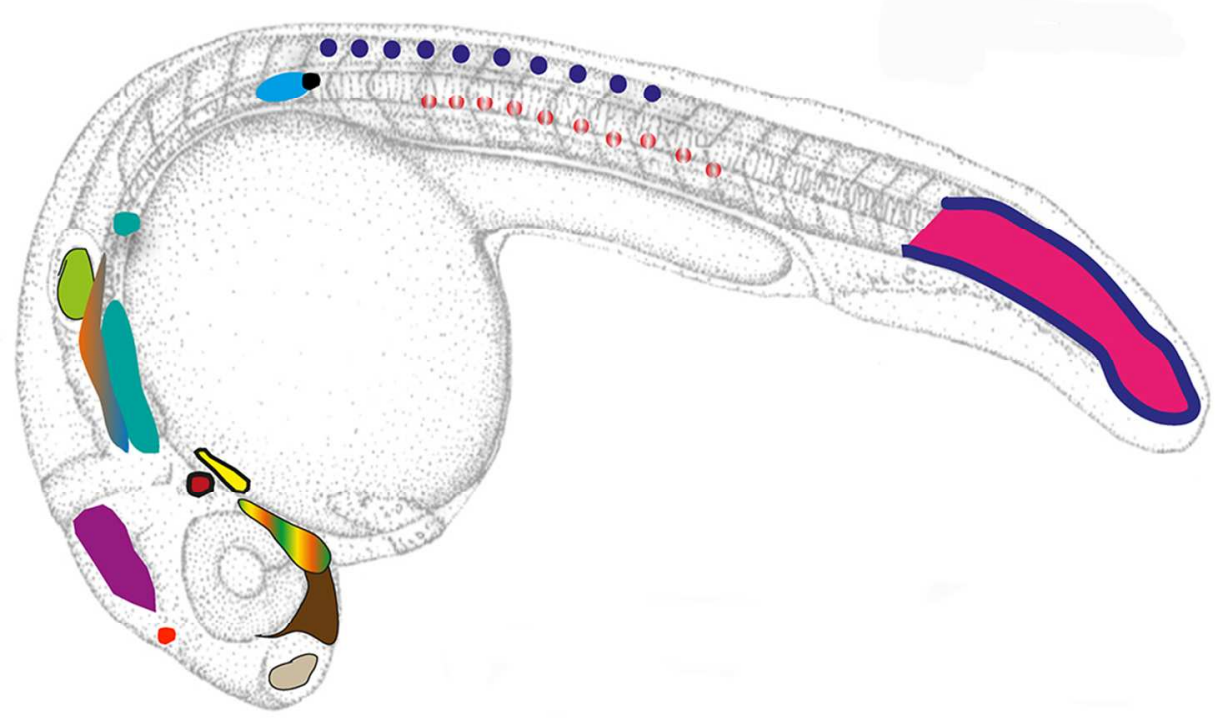

$97 \times 58 \mathrm{~mm}(300 \times 300$ DPI $)$

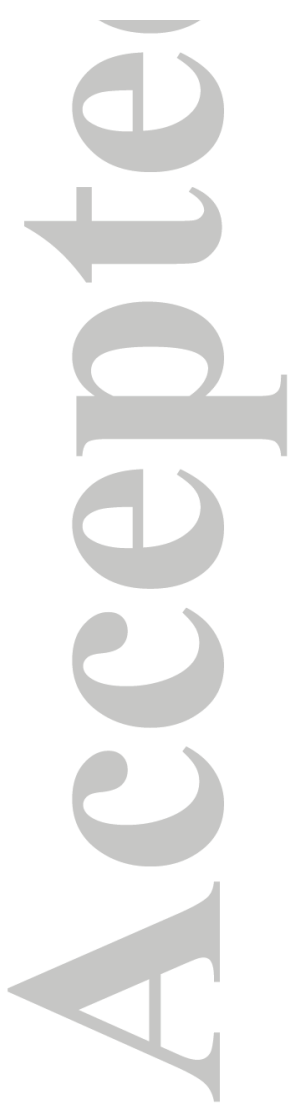

John Wiley \& Sons

This article is protected by copyright. All rights reserved. 
First examination of the expression profiles of the whole complement of neurotrophin and neurotrophin tyrosine kinase receptor genes in vertebrate embryogenesis. Our study offers novel routes for investigating the biological role of each neurotrophin and their combinatorial interaction with neurotrophin receptor tyrosine kinases.
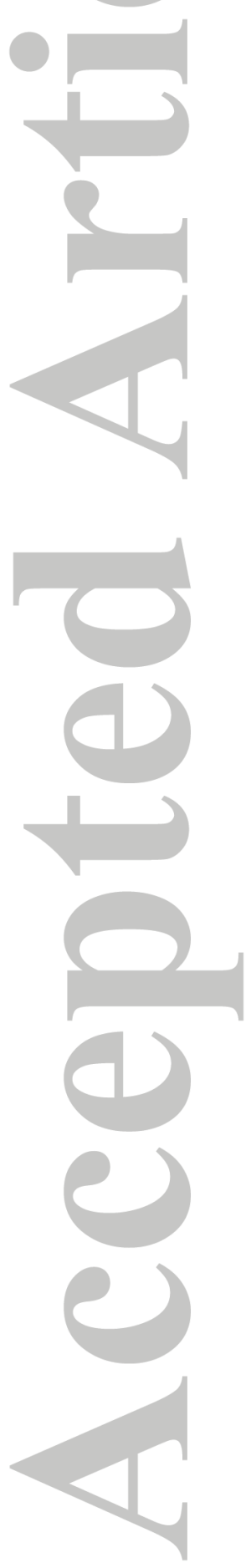